\title{
Microstructural Characterization of the U-9.1Mo Fuel/AA6061 Cladding Interface in Friction-Bonded Monolithic Fuel Plates Irradiated in the RERTR-6 Experiment
}

\author{
DENNIS D. KEISER Jr., JAN-FONG JUE, BRANDON MILLER, JIAN GAN, \\ ADAM ROBINSON, PAVEL MEDVEDEV, JAMES MADDEN, DAN WACHS, \\ CURTIS CLARK, and MITCH MEYER
}

\begin{abstract}
Low-enrichment $\left({ }^{235} \mathrm{U}<20 \mathrm{pct}\right) \mathrm{U}$-Mo monolithic fuel is being developed for use in research and test reactors. The earliest design for this fuel that was investigated via reactor testing consisted of a nominally U-10Mo fuel foil encased in AA6061 (Al-6061) cladding. For a fuel design to be deemed adequate for final use in a reactor, it must maintain dimensional stability and retain fission products throughout irradiation, which means that there must be good integrity at the fuel foil/cladding interface. To investigate the nature of the fuel/cladding interface for this fuel type after irradiation, fuel plates were fabricated using a friction bonding process, tested in INL's advanced test reactor (ATR), and then subsequently characterized using optical metallography, scanning electron microscopy, and transmission electron microscopy. Results of this characterization showed that the fuel/cladding interaction layers present at the U-Mo fuel/AA6061 cladding interface after fabrication became amorphous during irradiation. Up to two main interaction layers, based on composition, could be found at the fuel/cladding interface, depending on location. After irradiation, an Al-rich layer contained very few fission gas bubbles, but did exhibit Xe enrichment near the AA6061 cladding interface. Another layer, which contained more $\mathrm{Si}$, had more observable fission gas bubbles. In the samples produced using a focused ion beam at the interaction zone/AA6061 cladding interface, possible indications of porosity/debonding were found, which suggested that the interface in this location is relatively weak.
\end{abstract}

DOI: $10.1007 / \mathrm{s} 40553-015-0055-8$

(C) ASM International (ASM) and The Minerals, Metals \& Materials Society (TMS) 2015

\section{INTRODUCTION}

Low-enrichment $\quad\left({ }^{235} \mathrm{U}<20\right.$ pct $) \quad$ U-Mo monolithic fuel is being developed for use in research and test reactors. ${ }^{[1]}$ The earliest design for this fuel that was investigated via reactor testing was composed of a

DENNIS D. KEISER, Jr., JAN-FONG JUE, BRANDON MILLER, JIAN GAN, ADAM ROBINSON, PAVEL MEDVEDEV, JAMES MADDEN, DAN WACHS, CURTIS CLARK, and MITCH MEYER, Engineers, are with the Nuclear Fuels and Materials Division, Idaho National Laboratory, P.O. Box 1625, Idaho Falls, ID 83415-6188. Contact e-mail: dennis.keiser@inl.gov

This information was prepared as an account of work sponsored by an agency of the U. S. Government. Neither the U. S. Government nor any agency thereof, nor any of their employees, makes any warranty, express or implied, or assumes any legal liability or responsibility for the accuracy, completeness, or usefulness of any information, apparatus, product, or process disclosed, or represents that its use would not infringe privately owned rights. References herein to any specific commercial product, process, or service by trade name, trademark, manufacturer, or otherwise do not necessarily constitute or imply its endorsement, recommendation, or favoring by the U. S. Government or any agency thereof. The views and opinions of authors expressed herein do not necessarily state or reflect those of the U. S. Government or any agency thereof.

Manuscript submitted July 31, 2014

Article published online September 3, 2015
U-Mo fuel foil encased in Al-6061 cladding, where the maximum composition of the various alloy constituents, in at. pet, is $1.34 \mathrm{Mg}-0.78 \mathrm{Si}-0.34 \mathrm{Fe}-0.17 \mathrm{Cu}-0.10 \mathrm{Zn}-$ $0.09 \mathrm{Ti}-0.18 \mathrm{Cr}-96.92 \mathrm{Al}$. One technique that was investigated for fabricating a fuel plate of this design was called friction bonding (FB), which is similar to Friction Stir Welding, whereby a rotating tool is rastered over both cladding surfaces to impart bonding between the fuel foil and cladding. ${ }^{[2,3]}$ Another fabrication method that was investigated was a hot isostatic pressing (HIP) method using a processing temperature near $833 \mathrm{~K}$ $\left(560{ }^{\circ} \mathrm{C}\right) \cdot{ }^{[4]}$

One challenge in having a fuel plate design where a uranium alloy is in contact with AA6061 alloy is that brittle intermetallics can develop when these materials are brought into intimate contact and then heated during fabrication, ${ }^{[5,6]}$ and these intermetallics can possibly crack and cause debonding of a fuel plate. When using HIP at temperatures near $833 \mathrm{~K}\left(560^{\circ} \mathrm{C}\right)$, significant interaction can occur between the U-Mo fuel and cladding. ${ }^{[4]}$ However, by using a technique like FB to bond the cladding to the fuel, it may be possible to limit the development of the brittle U-Al intermetallic phases by keeping the time at high temperature relatively short during fuel plate processing, while still 
getting a good bond at the interface. Currently, monolithic fuel has been designed with a $\mathrm{Zr}$ diffusion barrier to help limit interaction between the fuel and cladding during HIP, but by using FB it could be possible to eliminate the use of a $\mathrm{Zr}$ diffusion barrier. The benefit of using a fuel without a diffusion barrier would be a reduction in the cost of the fuel, provided the fuel still exhibits acceptable irradiation performance. Acceptable irradiation performance for the fuel would be to maintain dimensional stability and retain fission products throughout irradiation, which means that there must be good integrity at the fuel foil/cladding interface. ${ }^{[7]}$

To investigate the nature of the fuel/cladding interface for a FB fuel plate without a $\mathrm{Zr}$ diffusion barrier after irradiation, selected small-scale fuel plates (mini-plates) that were tested in INL's Advanced Test Reactor (ATR) were subsequently characterized using optical metallography. ${ }^{[8]}$ To better understand the microstructures present at the fuel/cladding interface, two fuel plates were also characterized using scanning electron microscopy (SEM), and one was additionally characterized using transmission electron microscopy (TEM). The results of this work will be discussed in this paper.

\section{BACKGROUND}

As described in Cunningham and Adams, ${ }^{[9]}$ the interest in cladding $\mathrm{U}$ with $\mathrm{Al}$ dates back to 1942 . Al is an effective cladding material due to its low cost, ease of fabrication, low absorption cross section for thermal neutrons, good heat-transfer properties, and acceptable strength and ductility that can withstand thermal stresses and gradients that are encountered in reactors, lack of poison-forming tendencies, and lack of structural damage during irradiation. In order to effectively use aluminum as a cladding material, there must be a metal-to-metal bond at the fuel/cladding interface. This is necessary to facilitate the flow of heat across the interface. The use of a liquid metal bond is not an option since aluminum is attacked by most liquid metal.

In general, the combination of uranium and aluminum is incompatible for solid-state bonding. ${ }^{[9]}$ It was found early that brittle compound layers readily form at the fuel/cladding interface. It was observed that differences between $\mathrm{U}$ and $\mathrm{Al}$ in thermal expansion and thermal conductivity, along with resistance to flow under deformation, lead to additional challenges in using this fuel type. This meant that the use of Al to protect U was a difficult task. One of the challenges was the relatively fast interdiffusion of $\mathrm{U}$ and $\mathrm{Al}$. At $723 \mathrm{~K}$ $\left(450{ }^{\circ} \mathrm{C}\right)$, U will diffuse through a $750-\mu \mathrm{m}$-thick Al can in 4 days, and the result of this interaction can be formation of conical-shaped blisters that contain gas. The first mention of the interdiffusion of uranium and aluminum in relation to the failure of Al-clad fuel elements dates back to $1943 .{ }^{[9]}$ Diffusion couple experiments have been performed using $\mathrm{U}$ and $\mathrm{Al}$ at temperatures from $473 \mathrm{~K}$ to $663 \mathrm{~K} \quad\left(200{ }^{\circ} \mathrm{C}\right.$ to $\left.390{ }^{\circ} \mathrm{C}\right) .{ }^{[10]}$ It was observed that, depending on pressure and surface conditions, interaction occurred at temperatures as low as $573 \mathrm{~K}\left(300^{\circ} \mathrm{C}\right)$. During irradiation of a fuel plate, this interaction may be enhanced due to radiation-enhanced diffusion. X-ray analysis indicated that the interdiffusion zone was mostly composed of $\mathrm{UAl}_{3}$ intermetallic, with some $\mathrm{UAl}_{2}$ and $\mathrm{UAl}_{4}$. The clear line of demarcation between the intermetallic zone and both $\mathrm{U}$ and $\mathrm{Al}$ was interpreted to indicate limited solubility of $\mathrm{U}$ in $\mathrm{Al}$ and $\mathrm{Al}$ in $\mathrm{U}$, and it was concluded that the intermetallic phases bonded firmly to $\mathrm{U}$, but poorly to $\mathrm{Al}$, and the result was that fracture usually occurred at the $\mathrm{UAl}_{3}-\mathrm{Al}$ interface. ${ }^{[9]}$ Large voids can be observed in the interdiffusion zone of a $\mathrm{U} v s \mathrm{Al}$ diffusion couple, and in many cases the voids are near the $\mathrm{UAl}_{3}-\mathrm{Al}$ interface. Also, large cracks are commonly observed in a $\mathrm{U} v s \mathrm{Al}$ interdiffusion zone, due to its brittleness and a hardness that has been measured to be $500 \mathrm{DPH}$ at room temperature (U-10Mo has a value near $300 \mathrm{DPH}^{[11]}$ and AA6061-T6 cladding has a value near $107 \mathrm{DPH} .^{[12]}$ ). Easy fracturing of U-Al intermetallics has the potential to disrupt heat flow at the metal-to-metal interface. ${ }^{[10]}$

Due to the challenges associated with bonding $U$ to Al, much work was performed looking at diffusion barriers and "bonding aids." ${ }^{[13]}$ Barriers were of interest for cases where the operating temperature was above $473 \mathrm{~K}\left(200{ }^{\circ} \mathrm{C}\right)$, and bonding aids were needed to enhance heat flow across the fuel/cladding interface. It was found that many diffusion barriers impaired heat flow. For example, refractory oxides were effective diffusion barriers but they could not be applied as a continuous adherent film. An Al-Si alloy applied at the fuel/cladding interface was found to be a good diffusion barrier that also imparted good bonding. To apply the alloy for a rod-type fuel, $\mathrm{U}$ and $\mathrm{Al}$ were dipped into molten Al-Si eutectic in order to generate a good metal-to-metal bond. The adherent $\mathrm{U}(\mathrm{Al}, \mathrm{Si})_{3}$ phase that formed at the interface deterred diffusion in the $473 \mathrm{~K}$ to $623 \mathrm{~K}\left(200{ }^{\circ} \mathrm{C}\right.$ to $\left.350{ }^{\circ} \mathrm{C}\right)$ temperature range. However, due to the brittleness of the $\mathrm{U}(\mathrm{Al}, \mathrm{Si})_{3}$ phase, great care was needed when handling fuel pins in order to avoid fracturing the $\mathrm{U}(\mathrm{Al}, \mathrm{Si})_{3}$ phase. $\mathrm{Ni}$ was also a diffusion barrier that was studied. ${ }^{[13]}$ During hot pressing, it formed intermetallic compounds, yet with careful control of time, temperature, and pressure, a fairly adherent bond could be achieved.

Since U-Mo alloy is being used as the fuel for the LEU monolithic fuel plates for application in research and test reactors, and not $U$, it was of interest to see if U-Mo interacted with Al alloys in the same way as has been reported for $\mathrm{U}$ and $\mathrm{Al}$. When $\mathrm{U}$-Mo alloys interact with Al or Al-Si alloys, complex diffusional interactions take place that can produce various phases with undesirable growth kinetics. In U-Mo vs Al diffusion couples annealed at $823 \mathrm{~K}$ and $873 \mathrm{~K}\left(550{ }^{\circ} \mathrm{C}\right.$ and $\left.600{ }^{\circ} \mathrm{C}\right), \quad \mathrm{UAl}_{3}, \quad \mathrm{UAl}_{4}, \mathrm{U}_{6} \mathrm{Mo}_{4} \mathrm{Al}_{43}$, and $\mathrm{UMo}_{2} \mathrm{Al}_{20}$ phases were observed to develop in the interaction region. ${ }^{[14,15]}$ For diffusion couple experiments between U-Mo alloys and Al- $x$ wt pet $\mathrm{Si}(x=2$ and 5) alloys annealed at $823 \mathrm{~K}\left(550^{\circ} \mathrm{C}\right)$, the phases identified included $(\mathrm{U}, \mathrm{Mo})(\mathrm{Al}, \mathrm{Si})_{3}$ predominantly, and when $\mathrm{Si}$ concentrations in the interdiffusion zone were low, $\mathrm{U}_{6} \mathrm{Mo}_{4} \mathrm{Al}_{43}$ and $\mathrm{UMo}_{2} \mathrm{Al}_{20}$ phases were observed. Since 
AA6061 alloy is the specific alloy used as the cladding for monolithic fuels, diffusion couple experiments were performed using U-10Mo vs AA6061 solid-solid diffusion couples. ${ }^{[5,6]}$ Due to the number of alloying additions in AA6061 alloy, there is an increase in the available thermodynamic degrees of freedom, which allows for the possibility for the development of several different phases, even more than for a U-Mo vs $\mathrm{Al}$ or U-Mo vs Al-Si alloy couple. The results of the work using solid-solid diffusion couples showed that surface layers can dramatically affect diffusion behavior and that shorter annealing times result in the development of more uniform layers that are composed of a Si-rich region near the U-Mo alloy and an Al-rich region near the cladding. For longer times, layers become more non-uniform, where Al-rich "nodules" start to develop. At even longer times, the kinetics of the interaction become quite fast, faster than what is typically observed for diffusion couples between U-Mo and pure Al. In terms of the diffusion behavior of the $\mathrm{Fe}, \mathrm{Mg}$, and $\mathrm{Si}$ in the AA6061, which are the highest concentration alloy constituents besides $\mathrm{Al}$, the $\mathrm{Fe}$ is contained in precipitates in the interdiffusion zone and the $\mathrm{Mg}$ and $\mathrm{Si}$ are soluble in the diffusion layers. $\mathrm{Mg}$ is most enriched in the layer nearest the cladding, and $\mathrm{Si}$ is most enriched in the layer adjacent to the U-Mo. Overall the diffusion structures can be very complex and can contain many different phases depending on the temperature and time.

In addition to the solid-solid diffusion couples experiments that were performed with U-Mo alloys and AA6061 cladding, diffusion couple experiments have been performed using couples that were fabricated using a FB technique. ${ }^{[16,17]}$ In annealed friction stir welded U-7Mo/AA6061 diffusion couples, Mirandou et al.$^{[16]}$ showed that when couples are annealed at $823 \mathrm{~K}$ and $613 \mathrm{~K} \quad\left(550{ }^{\circ} \mathrm{C}\right.$ and $\left.340{ }^{\circ} \mathrm{C}\right)$ for $(1.5+1.5)$ and $(1560+1656)$ hours, respectively, a very irregular layer will develop at the U-7Mo/AA6061 cladding interface during the $823 \mathrm{~K}\left(550{ }^{\circ} \mathrm{C}\right)$ anneal, and the layer varies in thickness from 6 to $300 \mu \mathrm{m}$. Two different types of layers can comprise the interaction layer: a relatively thin "Type I" and a thicker "Type II" layer. The Type I layer contains negligible $\mathrm{Si}$, while the Type II layer contains from 10 to 14 at. pet Si. At $823 \mathrm{~K}\left(550^{\circ} \mathrm{C}\right)$, the orginial $\gamma-(\mathrm{U}, \mathrm{Mo})$ phase that comprises the U-7 wt pct Mo alloy will eventually decompose into $\alpha$-U and $\mathrm{U}_{2} \mathrm{Mo}$, forming a lamellar microstructure, and where these local transformed regions are near the U-7Mo/ AA6061 interface, it was observed that the thicker Type II interaction layer developed. Two phases were observed to comprise the Type II layer, viz. $\mathrm{UAl}_{3}$ and $\mathrm{U}_{6} \mathrm{Mo}_{4} \mathrm{Al}_{43}$. The $\mathrm{U}(\mathrm{Al}, \mathrm{Si})_{3}$ phase was observed in the Type I layer. $\mathrm{A}_{3} \mathrm{Si}_{5}$ phase was observed in the interaction layer for the couples annealed at $614 \mathrm{~K}$ $\left(340{ }^{\circ} \mathrm{C}\right)$, and the $\mathrm{Si}$ content $(55$ at. pct $\mathrm{Si}$ ) was much higher than the 17 at. pct Si observed in the interaction layer of the couples annealed at $823 \mathrm{~K}\left(550{ }^{\circ} \mathrm{C}\right)$. The work reported by Mirandou et al. ${ }^{[16]}$ suggests that the formation of "nodules" along the interface can be impacted by decomposition of the $\gamma$-(U,Mo) phase. Keiser $^{[17]}$ reported the results for U-7Mo/AA6061 and $\mathrm{U}-10 \mathrm{Mo} / \mathrm{AA} 6061$ couples annealed at $773 \mathrm{~K}\left(500{ }^{\circ} \mathrm{C}\right)$ for 30 minutes, and it was confirmed that decomposition of the $\gamma$-(U,Mo) phase results in increased interaction between the U-Mo alloy and the AA6061 cladding. Furthermore, there were indications that a $(\mathrm{U}, \mathrm{Mo}, \mathrm{Si})$ phase can form at the interface with negligible $\mathrm{Al}$, and this phase may be similar to the $\mathrm{U}_{3} \mathrm{Si}_{5}$ phase reported by Mirandou et al. ${ }^{[16]}$ for a U-7Mo vs AA6061 cladding diffusion couple annealed at $623 \mathrm{~K}\left(350{ }^{\circ} \mathrm{C}\right)$. For $\mathrm{U}-10 \mathrm{Mo}$-containing diffusion couples, the interaction zone appeared to contain two different interaction layers, based on composition: one enriched in $\mathrm{Si}$, and the other enriched in $\mathrm{Al}$, and at some regions along the interface, there may be only a Si-rich or Al-rich phase that can be resolved, instead of both.

In addition to controlled annealing experiments with diffusion couples, experiments were performed using $\mathrm{U}-x \operatorname{Mo}(x=7,8$, and 10) alloys, AA6061 cladding, and a HIP. ${ }^{[18]}$ By running the HIP at $833 \mathrm{~K}\left(560^{\circ} \mathrm{C}\right)$ and $104 \mathrm{MPa}$ for 90 minutes, it was demonstrated that the fuel/cladding interaction layer varied from less than a couple of microns in U-10Mo bearing mini-plates to $>100 \mu \mathrm{m}$ in U-7Mo bearing mini-plates. Areas of the fuel/cladding interaction layer were observed to be Si-rich, in that $>5$ wt pet $\mathrm{Si}$ was measured and only $\sim 0.6$ wt pet $\mathrm{Si}$ is present in the original cladding. For a $\mathrm{U}-8 \mathrm{Mo}$ bearing mini-plate, the interaction layer was, like for the U-7Mo case, $>100 \mu \mathrm{m}$ in thickness, and the formed interaction zone was very non-uniform and had "nodule"-like features similar to what was observed by Mirandou et al..$^{[16]}$ in their diffusion couples. When a U-7Mo fuel plate is in the HIP at $853 \mathrm{~K}\left(580{ }^{\circ} \mathrm{C}\right)$ for 3 hours, the $250-\mu \mathrm{m}$ fuel foil is almost completely consumed.

To determine the irradiation behavior of specific phases that comprise the interaction layers that form during interdiffusion between U-Mo alloys and $\mathrm{Al}$ and Al alloys, ion irradiation experiments have also been performed. ${ }^{[19,20]}$ Testing was performed on alloy samples that contained the same phases that also form in interdiffusion zones between U-Mo and Al-Si alloys. The results of ion irradiation experiments showed that the $\mathrm{U}_{6} \mathrm{Mo}_{4} \mathrm{Al}_{43}$ and $\mathrm{UMo}_{2} \mathrm{Al}_{20}$ phases that have been observed in interaction layers for annealed diffusion couples go amorphous at relatively low dpa values, while phases like $(\mathrm{U}, \mathrm{Mo})(\mathrm{Al}, \mathrm{Si})_{3}$ phases survive to higher dpa before they go amorphous. $\mathrm{U}_{6} \mathrm{Mo}_{4} \mathrm{Al}_{43}$ phase is the same phase that Mirandou et al. identified in the Type II interaction layer that formed in their U-7Mo/AA6061 cladding diffusion couples annealed at $823 \mathrm{~K}\left(550{ }^{\circ} \mathrm{C}\right) \cdot{ }^{[16]}$

Significant data are available for Al alloy-clad U-Mo dispersion fuels with $\mathrm{Al}$ or $\mathrm{Al}-\mathrm{Si}$ alloy matrices that have been irradiated using neutrons. The U-Mo alloy/matrix interfaces in these fuels have been characterized for a variety of samples after fabrication and after irradiation under different conditions. ${ }^{[21-27]}$ It has been observed that the U-Mo alloy/matrix interfaces for these fuel plates develop interaction layers during fabrication, and these layers are very similar to the ones observed at the U-9.1Mo/AA6061 cladding interface in the current samples. In dispersion fuels, any interaction layers that are present at the interface between U-Mo fuel and Al-Si 
alloy matrix after fabrication and that then grow further during irradiation go amorphous during irradiation. Additionally, fission gas bubbles can be observed in phases that are Si-rich, while for the Al-rich phases fission gas bubbles are infrequently observed in the actual layer but they are observed a the Al-rich layer/matrix interface. In dispersion fuels, poor performance of interaction layer phases has been concluded to contribute to eventual fuel plate failures, ${ }^{[28,29]}$ and it has been specifically suggested that the accumulation of fission products at the interaction layer/matrix interface leads to a weakening of the fuel meat of a fuel plate and eventual pillowing. ${ }^{[29]}$

\section{EXPERIMENTAL}

\section{A. Plate Fabrication}

The U-9.1 wt pet Mo (U-9.1Mo) fuel alloy used as feedstock for the monolithic fuel plates was produced by combining low-enriched uranium with molybdenum foil in an arc melting furnace. The goal of this test was to employ firs-of-a-kind fuel foils, and a device was designed to produce samples. The device for making foils ended up being a hand-cranked mill located in a radiological hood. The foils were rolled to a target of $250 \pm 25 \mu \mathrm{m}$. As the rolled foils typically underwent $\sim 90$ pet thickness reduction in the cold condition with no mid-process annealing, the amount of cold work was severe. It was determined that the as-rolled foils would, if left in the as-rolled condition, undergo severe cracking. This cracking was found to progress to the point of rendering a foil unusable within a few hours. Annealing was performed using electrical resistance to heat the foil to a softened condition. This apparatus consisted of a standard welding power supply, which was used to drive a current through the foil that was to be annealed. The foil was contained in an inert atmosphere of flowing argon. The argon protected the heated foil from exposure to air during processing and quenched the foil after the annealing. The foil was heated in a matter of seconds to the target annealing temperature of $1198 \mathrm{~K}$ $\left(925^{\circ} \mathrm{C}\right)$. The foil temperature was monitored by an optical pyrometer. After annealing, the foil was rapidly cooled back to room temperature. The AA6061 cladding was ordered in the T-6 hardness condition.

A Bridgeport milling machine was used for the RERTR-6 FB process. This is a solid-state process where a rotating tool is rastered across both sides of a fuel plate to produce good bonding at the U-9.1Mo foil/ AA6061 cladding interface. ${ }^{[2]}$ The thicknesses of the top and bottom plates were held within $25 \mu \mathrm{m}$. These thicknesses were not readily available from any commercial source, so AA6061 sheets were rolled to the desired thickness. A recess was machined in the bottom plate sized to fit the foil (see Figure 1). The area of this recess was slightly larger than the foil on the perimeter to allow the fuel foil to be easily fit (and remain) in the assembly despite some foil warping. For the FB process, over-sizing the area of the top and bottom plates was critical.

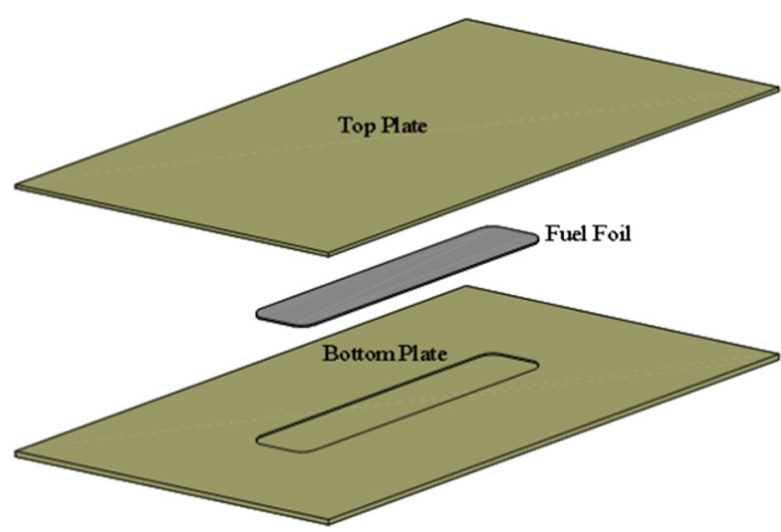

Fig. 1-Exploded view of monolithic fuel plate assembly.

After completion of the FB process, two additional fabrication steps were applied to the RERTR-6 fuel plates that are not typically used to fabricate current generation fuel plates. The first was called the "flattening step" and the second the "homogenization anneal." Both of these steps involved exposure of the fuel plates to high temperatures. The "flattening step" was employed due to warpage of the fuel plates as a result of $\mathrm{FB}$, which was too severe to allow for final processing (thinning, surface finishing, shearing, etc.). During this step, the plates were loaded into a heated platen hydraulic press heated to $658 \mathrm{~K}\left(385^{\circ} \mathrm{C}\right)$ and pressed at $\sim 1378 \mathrm{kPa}$ for 3 to 4 minutes. After this step, the plates were determined to be flat enough for the subsequent processing steps. The "homogenization anneal" step was employed to eliminate heterogeneous microstructures in the fuel plates that could be present after FB and potentially cause enhanced corrosion of the fuel plates. The homogenization anneal was performed at $773 \mathrm{~K}\left(500{ }^{\circ} \mathrm{C}\right)$ for 30 minutes in the heated uniaxial press under light force (typically $2.2 \mathrm{kN}$ ) to ensure good contact between the platens and the plate surface.

At the end of fuel plate fabrication, the cladding was pre-filmed with a Boehmite layer (at $458 \mathrm{~K}\left(185^{\circ} \mathrm{C}\right.$ ) for 4 hours in an autoclave) to control corrosion in the reactor. ${ }^{[30]}$ Taking into account the fact that local regions of a $\mathrm{FB}$ fuel plate only see temperatures up to about $573 \mathrm{~K}\left(300^{\circ} \mathrm{C}\right)$ for a few minutes during the $\mathrm{FB}$ process ${ }^{[2]}$ and $658 \mathrm{~K}\left(358^{\circ} \mathrm{C}\right)$ for a few minutes during the flattening step, the bulk of the high-temperature exposure of a fuel plate occurs during the homogenization anneal [773 $\mathrm{K}\left(500{ }^{\circ} \mathrm{C}\right)$ for 30 minutes].

\section{B. Irradiation Testing}

Irradiation testing details for the RERTR-6 experiment are discussed in Reference 31. This experiment was designed to act as the first significant test of the U-Mo monolithic fuel form. The mini-plate fuel geometry (shown in Figure 2) was selected for this test to allow for rapid and relatively inexpensive testing of a wide variety of fuel compositions. The experiment utilized irradiation hardware designed to perform previous mini-plate tests in ATR. The monolithic foils were $8.26 \mathrm{~cm}$ long, 


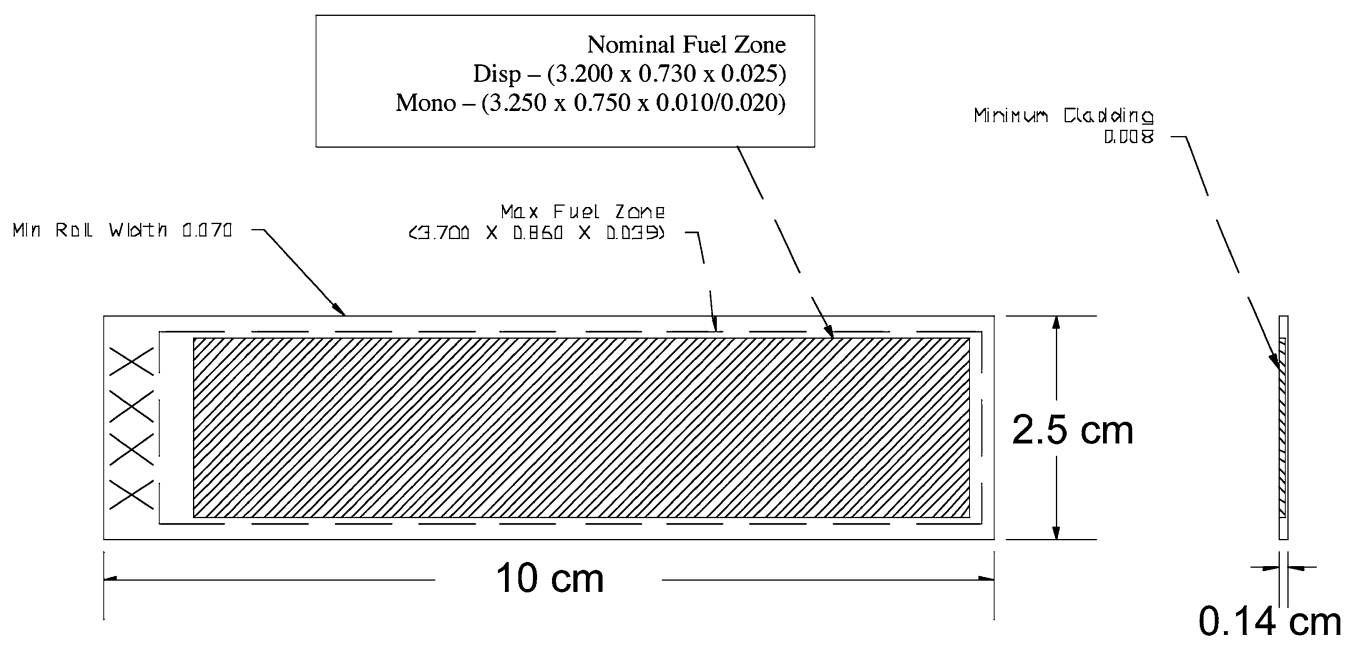

Fig. 2-Example of a sketch for a typical RERTR-6 mini-plate, where dimensions are in inches. Fuel plates are $10 \mathrm{~cm}$ long by $2.5 \mathrm{~cm}$ wide by $0.14 \mathrm{~cm}$ thick.

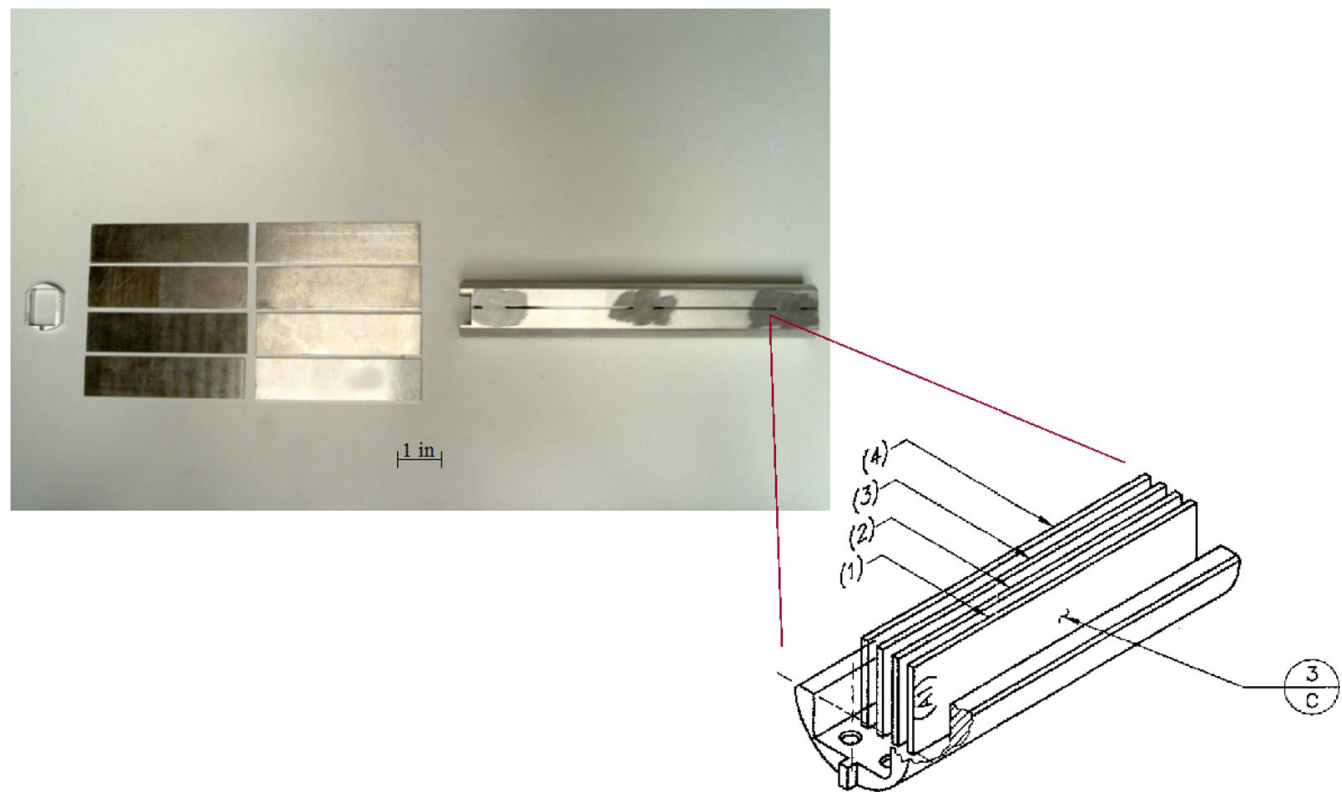

Fig. 3-RERTR-6 mini-plate capsule.

$1.91 \mathrm{~cm}$ wide, and had a corner radius of $0.318 \mathrm{~cm}$. The foil thickness was $0.0254 \mathrm{~cm}$, and the total fuel zone volume was $0.40 \mathrm{~cm}^{3}$. The final fuel plates were $10 \mathrm{~cm}$ long by $2.5 \mathrm{~cm}$ wide by $0.14 \mathrm{~cm}$ thick (see Figure 2).

The RERTR mini-plate irradiation hardware was designed to fit in an ATR Large B-position and was directly cooled by ATR primary coolant, which entered at approximately $325 \mathrm{~K}\left(52{ }^{\circ} \mathrm{C}\right)$ and was driven by a roughly $531 \mathrm{kPa}(77 \mathrm{psi})$ inlet to out pressure differential. The hardware consisted of a thin wall basket with an upper lip that allowed the test train to hang from the mechanical structure above the ATR core. The basket held four capsules and two spacers. Each capsule contained eight mini-plates (see Figure 3). Spacers were inserted above and below the four, fueled capsules to center the experiment across the ATR core centerline. The experiment basket was positioned so that one edge of the mini-plates faced the core. A strong neutron flux gradient existed across the width of the plates, and hence, one edge ran at considerably higher power $(\sim 35$ pct $)$ than the other. The experiment was loaded into ATR in May 2005 in experimental position B-12, where it remained for three cycles $(134 \mathrm{~B}, 135 \mathrm{~B}$, and $135 \mathrm{C}$ ) for a total of 135 effective full power days (EFPD). Average burn-up of the 19.7 pct enriched fuel was 35 to 49 pct depending on the location in the experiment. Burn-up was calculated from the as-run physics calculations. For the two fuel plates that were microstructurally characterized (viz. L1F040 and L1F100), the results are listed in Table I. The Beginning-Of-Life (BOL) fuel temperatures were $<473 \mathrm{~K}$, and the peak heat flux was $145 \mathrm{~W} / \mathrm{cm}^{2}$. The calculated average fission densities (excluding $\mathrm{Pu}$ fissions) for L1F040 and L1F100 are $3.15 \times 10^{21}$ and 
Table I. Burn-up Data Based on As-run Physics Calculations for Fuel at 19.7 pct ${ }^{235} \mathrm{U}$ Enrichment

\begin{tabular}{lccr}
\hline Plate Number & Foil Average Burn-up $\left(\right.$ Pct $\left.^{235} \mathrm{U}\right)$ & Burn-up Core Edge* $\left(\right.$ Pct $\left.^{235} \mathrm{U}\right)$ & Burn-up Outer Edge (Pct $\left.^{235} \mathrm{U}\right)$ \\
\hline L1F040 & 45.66 & 52.5 & 38.9 \\
L1F100 & 46.29 & 53.2 & 39.4 \\
\hline
\end{tabular}

*Fuel plates were oriented perpendicular to the core, and the fuel plate surfaces close to the core are called the "core edge" and the surfaces furthest from the core is the "outer edge".

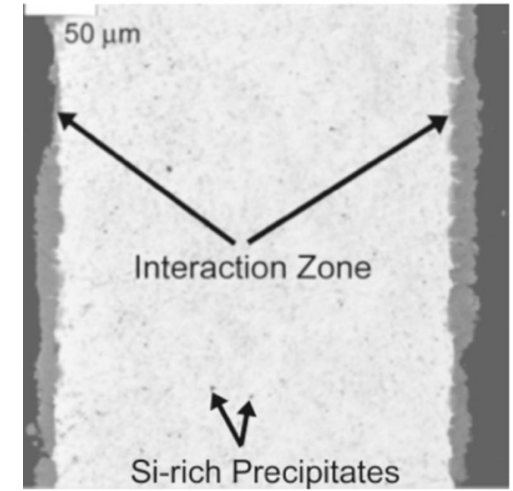

(a)

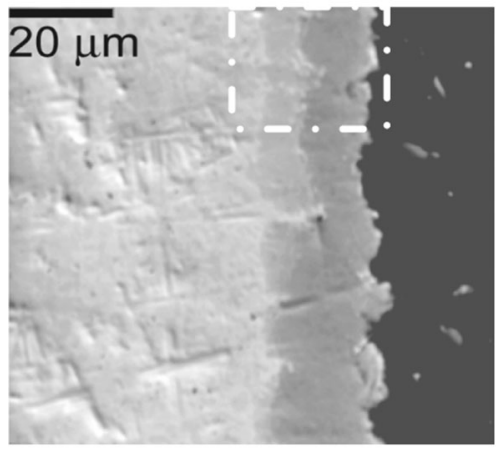

(c)

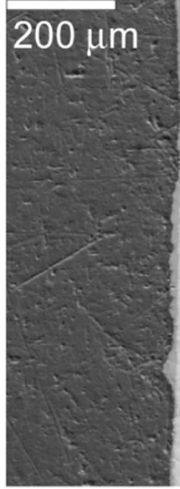

(b)

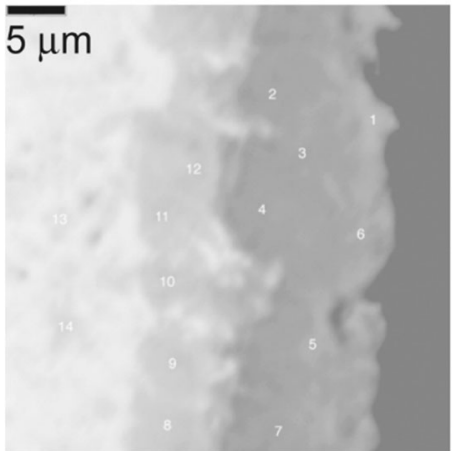

(d)

Fig. 4-A BSE image $(a)$ and SE image $(b)$ of cross section of fuel plate L1F080, where an interaction zone with a variation in thickness could be observed at the interface between the U-9.1Mo (bright) and AA6061 cladding (black). Si-rich precipitates were observed in the U-9.1 Mo foil. (c) is a high-magnification SE image of the interaction zone and $(d)$ is a BSE image of the box area depicted in (c) that also shows locations where point-to-point compositional analysis was performed on two layers that differed in contrast.

$3.33 \times 10^{21}$ fissions $/ \mathrm{cm}^{3}$, respectively. The peak fission densities at the core edge for fuel plates L1F040 and $\mathrm{L} 1 \mathrm{~F} 100$ are $4.4 \times 10^{2 \mathrm{P}}$ and $4.6 \times 10^{21}$ fissions $/ \mathrm{cm}^{3}$, respectively.

\section{Microstructural Characterization}

To determine the microstructure at the foil/cladding interface before irradiation, samples were sliced from an as-fabricated archive fuel plate (L1F080), mounted and metallographically prepared for characterization using scanning electron microscopy (SEM). Once the starting microstructure of a FB fuel plate was identified, it could then be compared to irradiated fuel microstructures to determine the effect of irradiation on microstructural development. SEM analysis consisted of imaging using secondary electron (SE) and backscattered electrons (BSE), and of performing compositional analysis using
Table II. Compositions Measured (Atomic Percent) Using EDS Standardless Analysis Performed at the Point Locations Identified in Fig. 4(d)

\begin{tabular}{lcccr}
\hline Label & $\mathrm{U}$ & $\mathrm{Mo}$ & $\mathrm{Al}$ & $\mathrm{Si}$ \\
\hline 1 & 19.0 & 1.5 & 61.6 & 17.8 \\
2 & 13.8 & 4.0 & 71.0 & 9.7 \\
3 & 14.7 & 3.7 & 70.2 & 10.8 \\
4 & 14.1 & 4.1 & 67.1 & 11.5 \\
5 & 18.0 & 4.1 & 66.9 & 17.3 \\
6 & 17.4 & 2.5 & 62.2 & 16.4 \\
7 & 14.7 & 3.6 & 70.6 & 10.7 \\
8 & 31.0 & 9.3 & 18.6 & 45.3 \\
9 & 31.7 & 9.0 & 14.7 & 45.0 \\
10 & 31.4 & 7.0 & 15.3 & 44.4 \\
11 & 30.4 & 10.0 & 15.5 & 42.6 \\
12 & 25.7 & 7.1 & 21.8 & 40.1 \\
\hline \multicolumn{4}{r}{ Mg was not measured in this analysis. } \\
\hline \multicolumn{5}{r}{} \\
\hline
\end{tabular}


energy dispersive spectroscopy (EDS) and wavelength dispersive spectroscopy (WDS). To determine the microstructure for irradiated fuel, L1F040 and L1F100 were selected for characterization. Optical metallography samples were produced from these fuel plates in the Hot Fuel Examination Facility (HFEF) using a slow-speed saw. Images were taken from cross sections produced at the midplane. For electron microscopy, two approaches were employed for producing samples. The first approach utilized a pneumatic press to generate a $1.4 \mathrm{~mm} \times$ $1.0 \mathrm{~mm}$ cylinder from the L1F100 fuel plate (this technique had been successfully employed for U-Mo dispersion fuels). The second approach utilized a slow-speed saw, whereby a 1-mm-wide, transverse cross section was sliced from the fuel plate and then mounted on an Al plate to give it stability. Approximately, 1.4-mm-thick sections were then cut from the mounted piece, mounted in epoxy, and metallographically polished. SEM/EDS/ WDS analysis was then performed on these types of samples from fuel plates L1F040 and L1F100. Additional characterization samples were produced from the mounted L1F040 samples using a focused ion beam (FIB). These samples were used for SEM imaging and analysis using transmission electron microscopy (TEM).

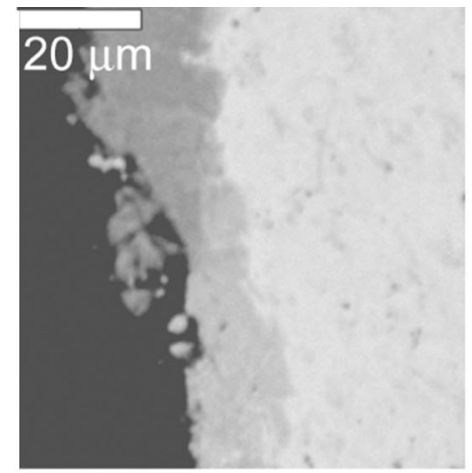

(a)

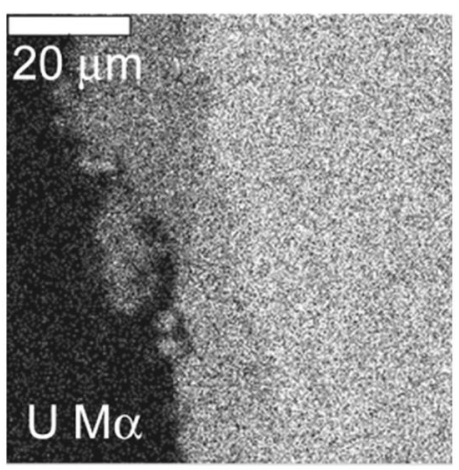

(d)

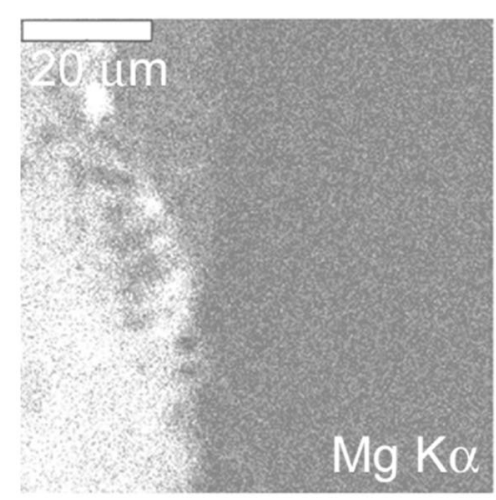

(g)

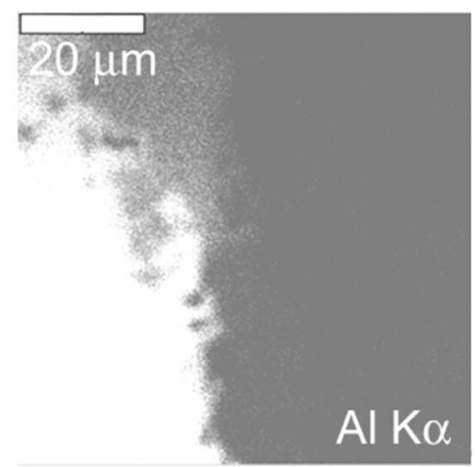

(b)

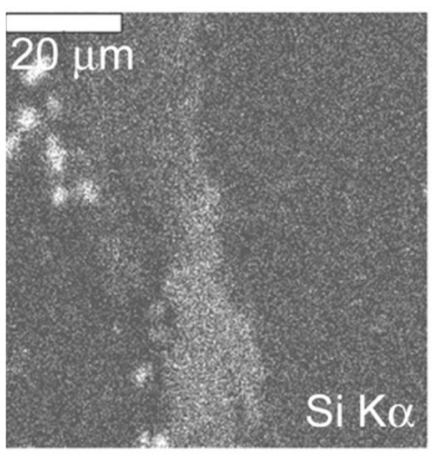

(e)

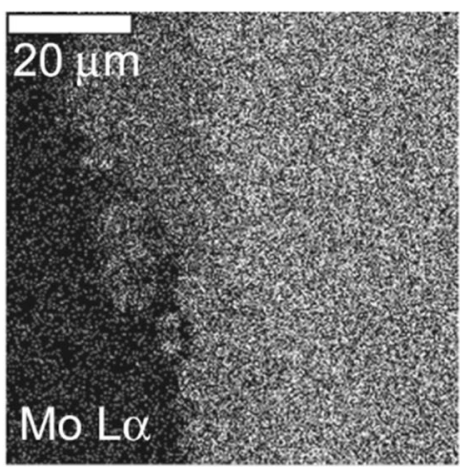

(c)

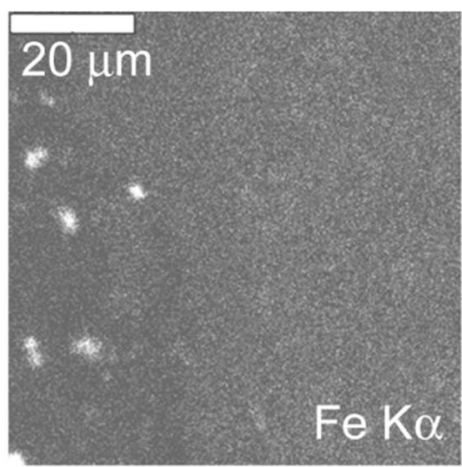

(f) 


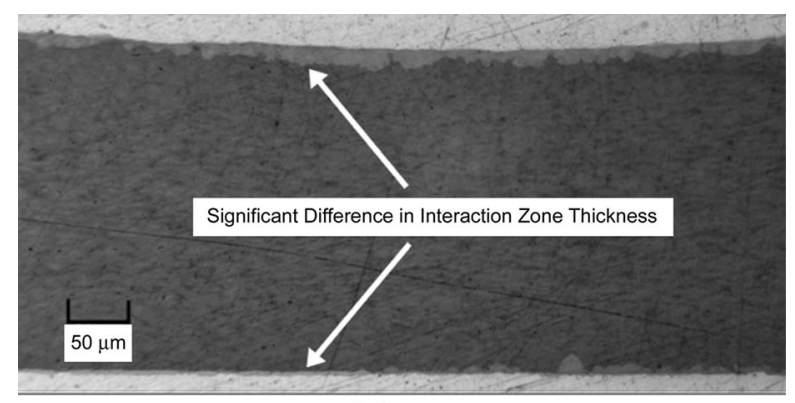

(a)

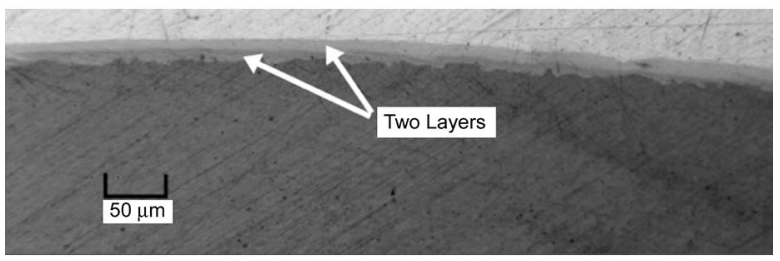

(b)

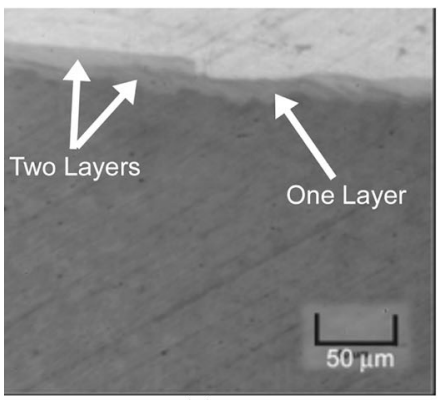

(c)

Fig. 6 - Optical images ( $a$ through $c$ ) from fuel plate L1F100 showing the U-9.1Mo foil (dark) and AA6061 cladding (bright) and interaction zone of varying thickness (medium contrast) present along the foil/cladding interfaces. Based on morphology, two different layers appear to comprise the interaction zone (b), but in some locations one layer comprises the interaction zone (c).

\section{RESULTS}

\section{A. As-Fabricated Fuel Plate Analysis}

Figure 4 shows SEM images of the microstructure observed for the as-fabricated fuel plate L1F080. The SEM/EDS/WDS analysis results showed that some impurities, Si-rich phases, were present in the U-9.1Mo, and an interaction zone was present between the U-9.1Mo and the AA6061 cladding. This zone formed during the fuel fabrication steps due to interaction between the U-9.1Mo foil and the AA6061 cladding to produce a $(\mathrm{U}, \mathrm{Mo}, \mathrm{Al}, \mathrm{Si})$ interaction zone that was composed of two individual layers. Figure 4(d) shows the locations where point-to-point compositional analysis was performed in each layer, and Table II shows the results of this analysis. The layer adjacent to the cladding was enriched in $\mathrm{Al}$ (points 1 to 7 in Table II), and the layer adjacent to the fuel was enriched in $\mathrm{Si}$ (points 8 to 12 in Table II). Moving along the fuel/cladding interface, significant variability in interaction zone thickness was observed. In some areas along

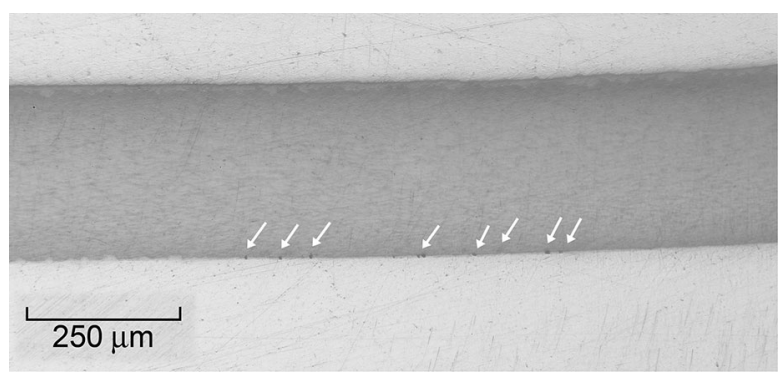

Fig. 7-Optical images for fuel plate L1F100 showing the U-9.1Mo foil (dark) and AA6061 cladding (bright) with possible pores (arrows) present along the foil/cladding interface.

the fuel/cladding interface, the two layers were each a couple of microns thick, and elsewhere they were each around 10 microns thick (for a total zone thickness of around $20 \mu \mathrm{m}$ ). Some regions were observed where the Al-rich layer comprised almost the complete thickness of the interaction zone. Figure 5 shows a BSE image and WDS X-ray maps for Al, Mo, U, Si, Fe, and Mg that were taken at the fuel/cladding interface. The Mg X-ray map shows that the Al-rich layer also contained a relatively high concentration of $\mathrm{Mg}$.

\section{B. As-Irradiated Fuel Plate Analysis}

\section{Optical metallography}

a. L1F100. Optical images of the L1F100 fuel plate microstructure are presented in Figure 6. An interaction zone is present at the interface between the U-9.1Mo foil and the AA6061 cladding that can exhibit significant differences in thickness. In some locations, this interaction zone approaches twenty microns in thickness. Based on morphology, two different layers comprise the interaction zone in most locations, but in some locations only one layer is observed. The optical image in Figure 7 shows locations where pores may be present along the foil/cladding interface. The effect of sample preparation on these features is not clear.

b. L1F040. Optical images of the L1F040 fuel plate microstructure are presented in Figure 8. Interaction layers can be observed at the interface between the U-9.1Mo foil and AA6061 cladding. The reaction layer thickness between the cladding and the foil was $\sim 3 \mu \mathrm{m}$ across the entire width of the plate for the one cross section that was analyzed. For this one cross section, there was no sign of the non-uniform reaction layer that was observed for the as-fabricated archive fuel plate (see Figure 4) and for the fuel plate L1F100.

\section{SEM analysis}

a. L1F100. The L1F100 sample contained two regions with intact U-9.1Mo/AA6061 cladding interface. Higher magnification images of this interface are shown in Figure 9. 


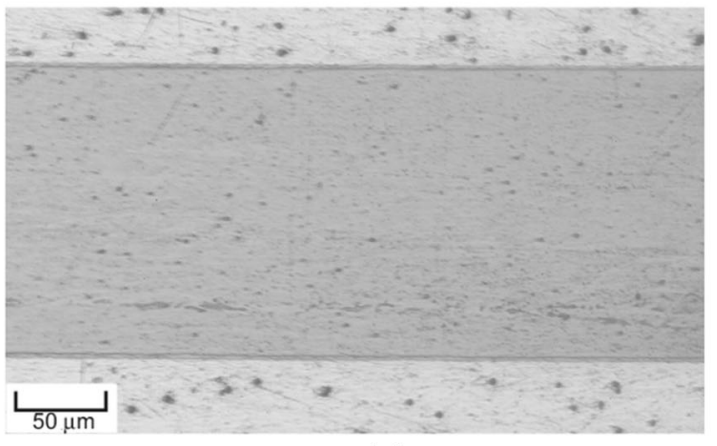

(a)

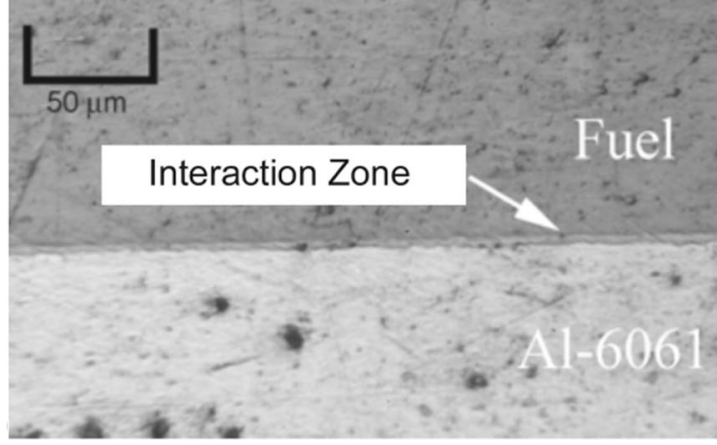

(b)

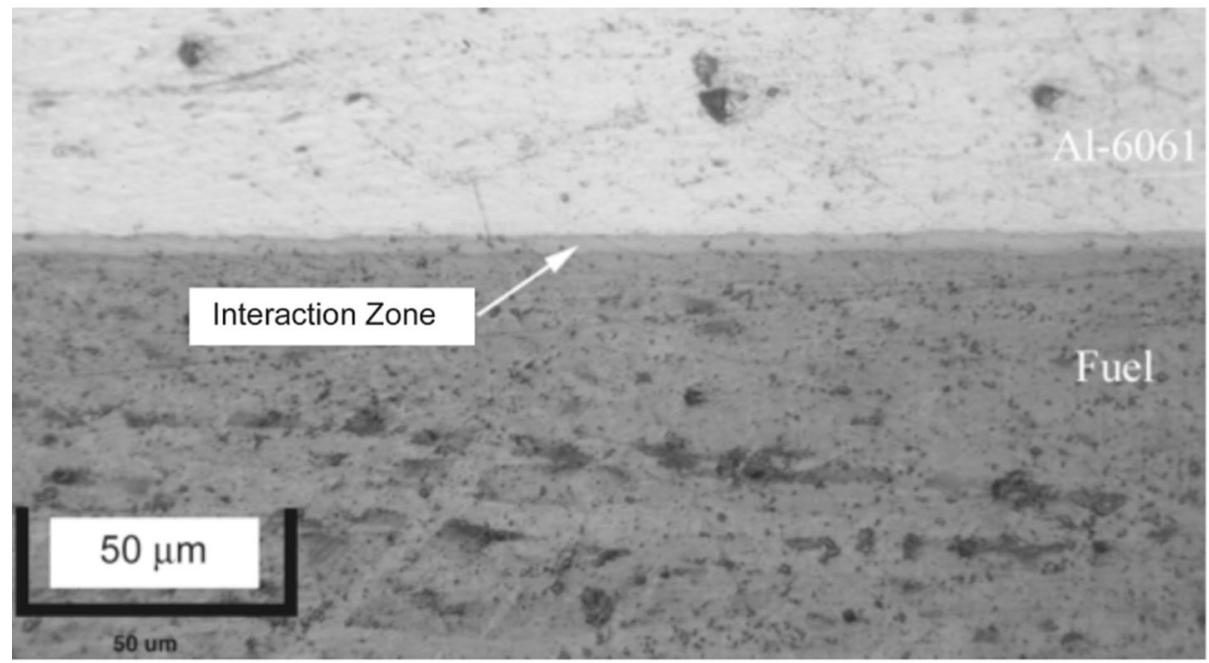

(c)

Fig. 8- Optical images at various locations along a transverse cross section taken from fuel plate L1F040.

Figure 10 shows $\mathrm{X}$-ray maps for $\mathrm{U}, \mathrm{Mo}, \mathrm{Al}$, and $\mathrm{Si}$ that were produced where an interaction layer between 5 and $10 \mu \mathrm{m}$ thick had developed at the U-9.1Mo/ AA6061 cladding interface in the sample from the high-flux side of the fuel plate. It can be observed that two types of phases were present, where one phase was $\mathrm{Si}$ rich and the other Si deficient. The Si-rich precipitates that were present in the U-9.1Mo in the as-fabricated fuel (Figure 4) are also present in the U-9.1Mo in the irradiated fuel plate. In Figure 11, a Si X-ray map is presented for a location where a relatively thin, Si-containing interaction layer was observed.

Characterization of this sample demonstrated that utilization of a punching process for generating SEM characterization samples from irradiated monolithic fuel plates is not an effective way to generate ideal samples. Due to the mechanical damage imparted onto the brittle sample and the fact that the material fractures into multiple pieces during punching, another approach was needed for producing samples where the final sample remained more intact. This would enable for more effective characterization of the microstructure, particularly at interfaces. The slow-speed saw cutting approach mentioned earlier was developed to allow for the production of samples from a full transverse cross section of a fuel plate that better retained their original arrangement where a monolithic fuel piece was contained between two pieces of cladding.

b. L1F040. Two L1F040 samples were produced from a transverse cross section of the fuel plate using the newly developed sample cutting approach. Low-magnification images of the two samples (A and B) are presented in Figure 12. Good contact was observed between fuel and cladding at both interfaces for sample $\mathrm{A}$ and at one interface for sample B.

Sample A SEM and TEM characterization were both performed on the U-9.1Mo/AA6061 interface for Sample A. Figure 13 shows a BSE image and X-ray maps for $\mathrm{U}, \mathrm{Mo}, \mathrm{Al}, \mathrm{Si}, \mathrm{Mg}$, and $\mathrm{Xe}$ at a representative location 


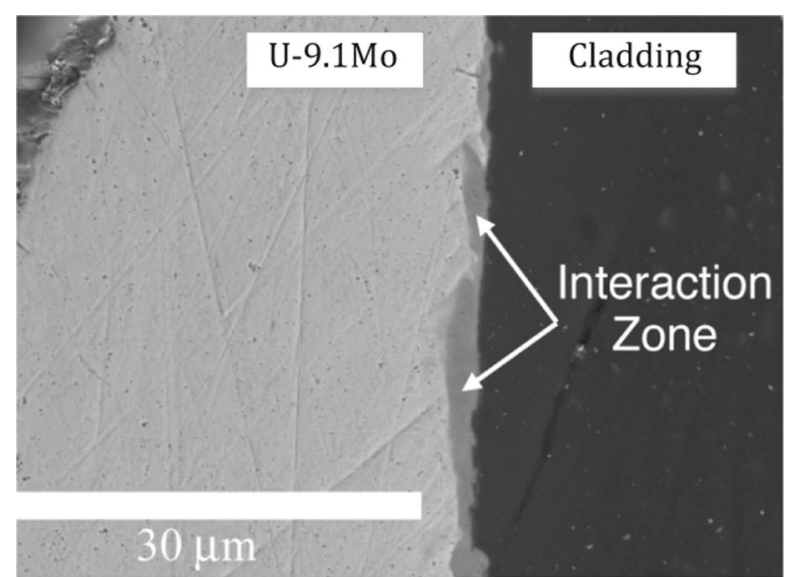

(a)

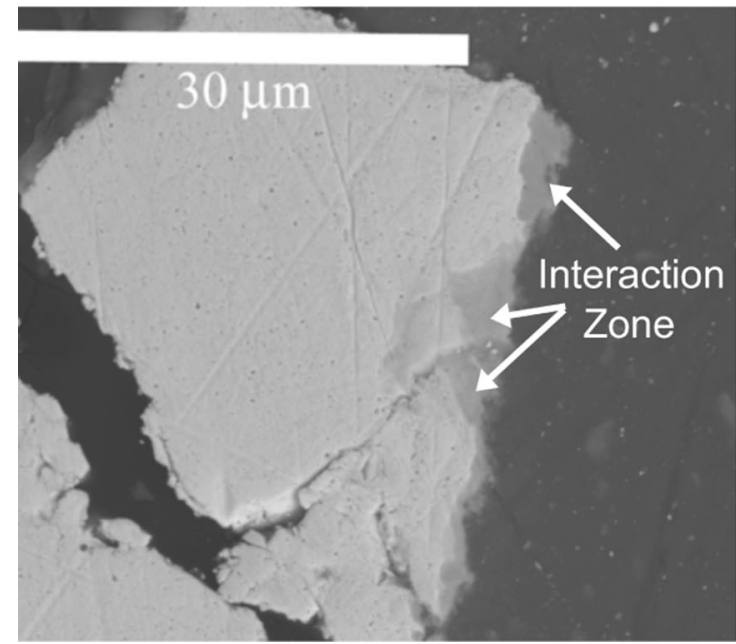

(b)

Fig. 9-SEM images of two locations $(a, b)$ along the U-9.1Mo/ AA6061 cladding interface for the sample from L1F100.

along the U-9.1Mo/AA6061 interface. A relatively high Si concentration was present in an interaction zone that was observed, and the cladding constituent $\mathrm{Mg}$ was also enriched in the interaction zone. The fission product Xe extended from the fuel into the cladding. In Figure 14, a BSE image and Xe X-ray map at another location along the U-9.1Mo/AA6061 cladding interface are presented, along with a line scan (in counts) that was taken at the U-9.1Mo/AA6061 cladding interface. Variability in Xe counts was observed moving across the U-9.1Mo/ AA6061 cladding interface. Two FIB samples were taken at the U-9.1Mo/AA6061 cladding interface. Initially, cross sections were produced at different locations along the interface (see Figure 15(a)) to identify the representative microstructure. Based on a survey of these microstructures, two FIB samples were produced for analysis that captured the microstructure that was representative of what was observed for the cross-section samples (see Figure 15(b)). At the
U-9.1Mo/AA6061 cladding interface for both samples, evidence of possible debonding and/or porosity was apparent between the interaction zone and the AA6061 cladding, which may be partly due to the presence of Xe fission gas at that specific location (see Figure 16(a)).

Using the FIB sample shown in Figure 16(c), TEM analysis was performed of the microstructure at the U-9.1Mo/AA6061 interface. A TEM micrograph of the observed microstructure is presented in Figure 17. As was the case for the microstructure observed using SEM (see Figure 16), two main layers were observed. Figure 18 shows locations where EDS analysis was performed (indicated A to P). The layer closest to the unreacted U-9.1Mo, layer 1 , had an approximate composition, in atomic percent, of $55 \mathrm{U}-25 \mathrm{Mo}-15 \mathrm{Si}-5 \mathrm{Al}$. As for the SEM analysis, fission gas bubbles could be observed in this layer (see Figure 18(a): indicated by arrows). Layer 2 contained less $\mathrm{Si}$, and it had an approximate composition, in atomic percent, of 14U-5Mo-(2-7)Si-75Al. Based on electron diffraction, any phases present in this layer were amorphous (see Figure 18(b)). Adjacent to the unreacted cladding was a layer composed of Mg-rich precipitates. EDS spot analysis of this region showed the local variation in $\mathrm{Mg}$ around the precipitates was between 8 and 12 at. pct, and regions away from the precipitates and closer to layer 2 contained less $\mathrm{Mg}$ (around 2 at. pct).

Sample B Only SEM characterization was performed at the U-91.Mo/AA6061 interface for sample B. Figure 19 shows a BSE image and X-ray maps for U, $\mathrm{Mo}, \mathrm{Al}, \mathrm{Si}, \mathrm{Mg}$, and $\mathrm{Xe}$ at a representative location along the U-9.1Mo/AA6061 interface. An interaction zone can be observed with $\mathrm{Si}$ heterogeneously distributed, and the cladding constituent $\mathrm{Mg}$ is enriched at the interaction zone/AA6061 interface. The fission product $\mathrm{Xe}$ is at a relatively high concentration at the interaction zone/AA60601 cladding interface. In order to characterize a sample with the least amount of mechanical damage due to polishing, one FIB sample was taken at the U-9.1Mo/AA6061 cladding interface (see Figure 20). Both a relatively thick Al-rich layer (Figure 20(c): layer 2) and relatively thin Si-rich layer (Figure 20(c): layer 1) is observed. In Figure 20(b), the Si-rich layer, as indicated with arrows, is observable along a relatively short distance along the interface, and in Figure 20(c), the Si-rich layer can be resolved along a longer distance along the interface. Overall, the interaction zone thickness was composed of more of the Al-rich phase, and less of the Si-rich phase, compared to what was observed for sample A.

\section{DISCUSSION}

Based on the results of SEM and TEM characterization performed on samples taken at the fuel/AA6061 cladding interface using a FIB for the irradiated fuel plates L1F040 and L1F100, the phases that develop at this interface are similar to those observed for similar 


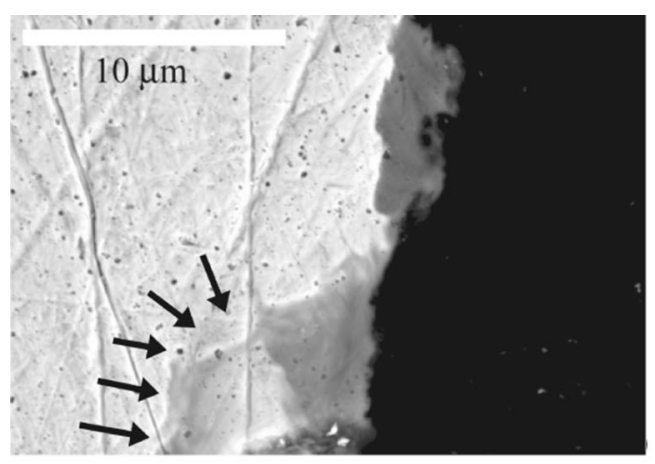

(a)

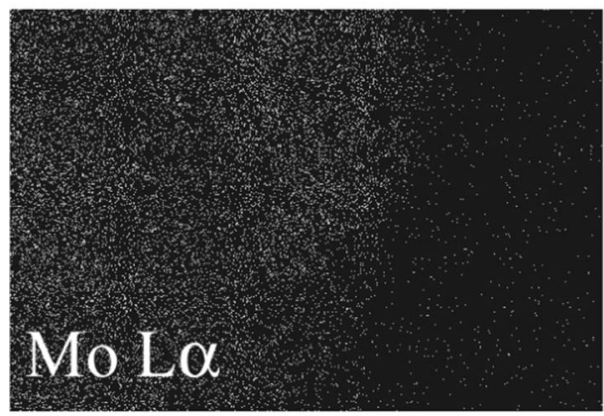

(c)

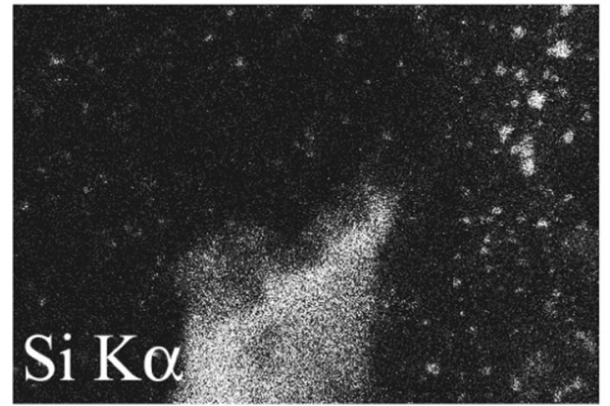

(e)

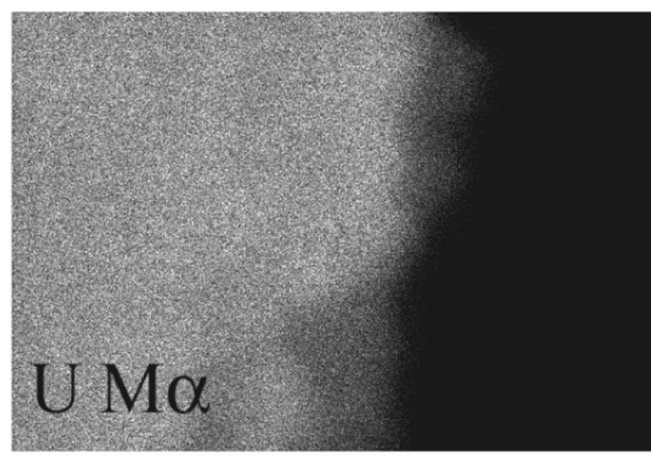

(b)

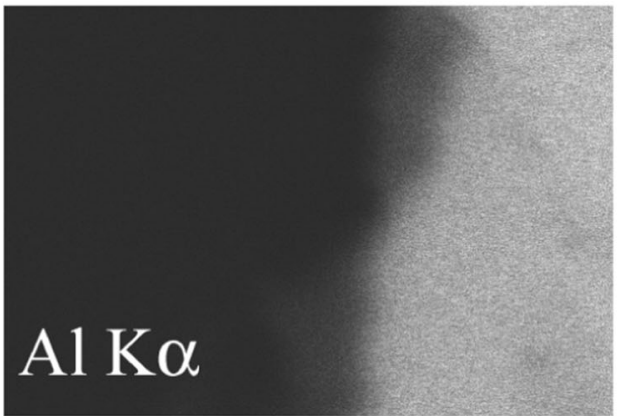

(d)

Fig. 10 - Backscattered electron image $(a)$ and WDS X-ray maps for $(b) \mathrm{U},(c) \mathrm{Mo},(d) \mathrm{Al}$, and $(e)$ Si taken at the foil/cladding interface of the L1F100 high-flux sample. Arrows in (a) highlight the areas in the microstructure where Si penetration has occurred.

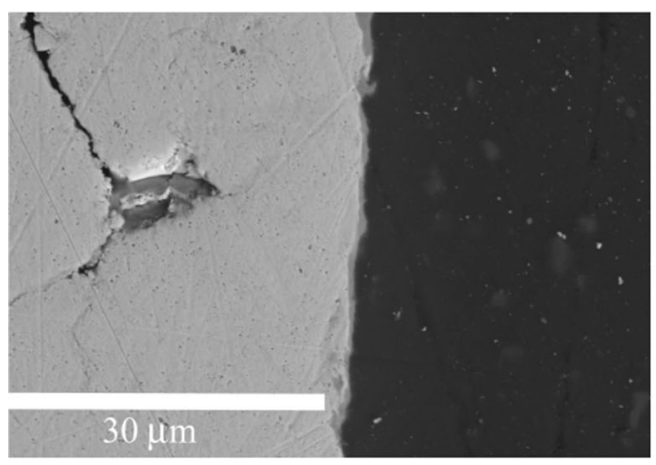

(a)

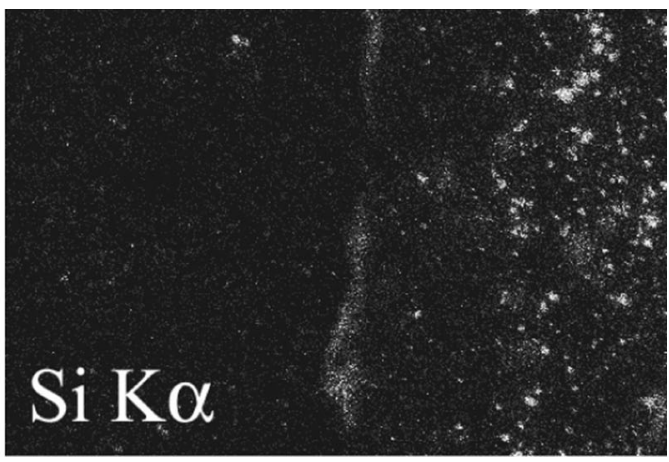

(b)

Fig. 11-Backscattered electron image $(a)$ and Si WDS X-ray map $(b)$ at the foil/cladding interface. 


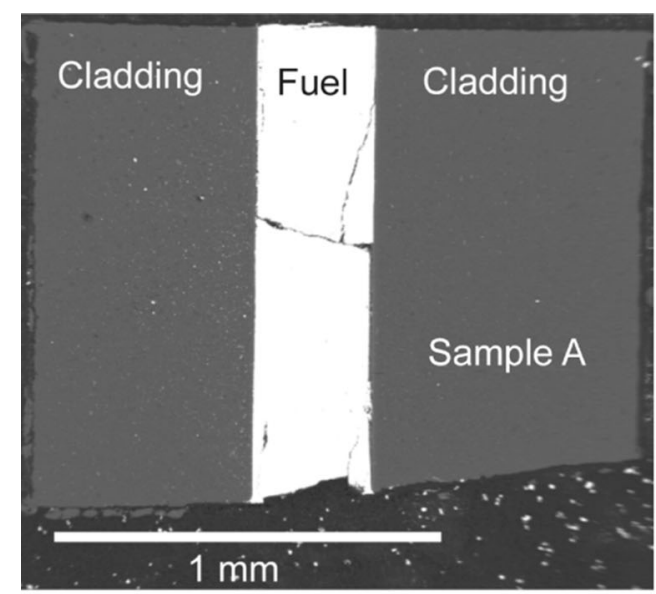

(a)

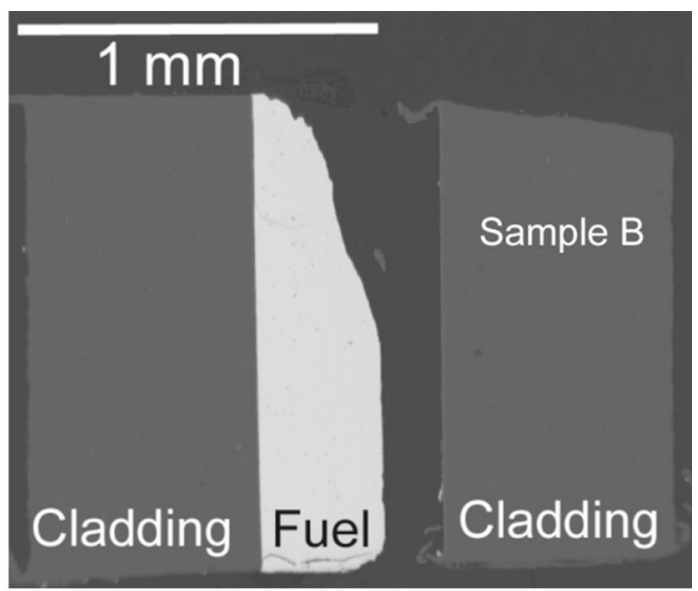

(b)

Fig. 12-BSE images of $(a)$ sample A and $(b)$ sample B taken from fuel plate L1F040. Mounting material has filled in the gap between the fuel and cladding for sample $\mathrm{B}$.

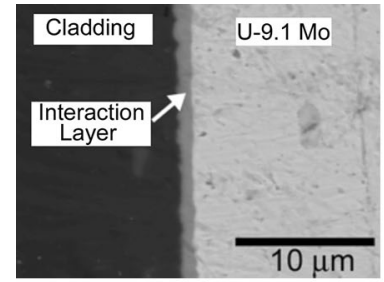

(a)

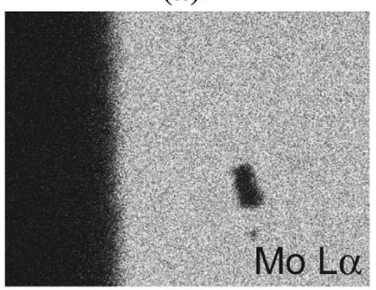

(c)

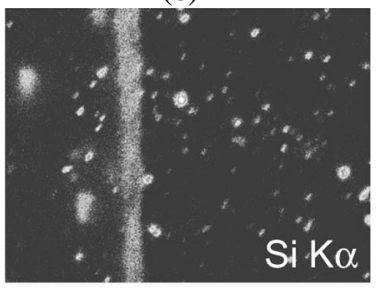

(e)

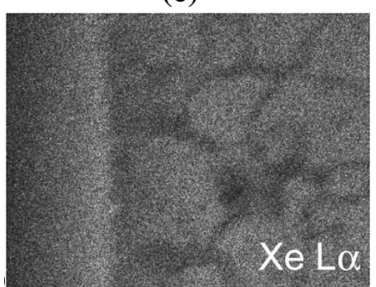

(g)

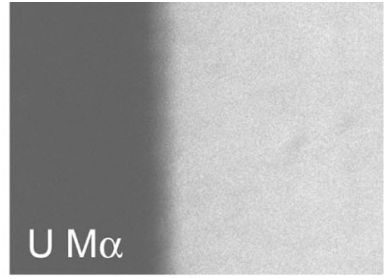

(b)

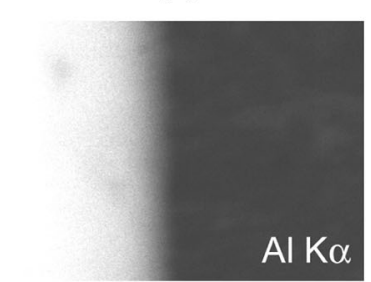

(d)

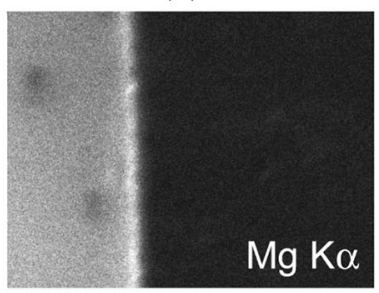

(f)
Fig. 13-BSE image (a) and X-ray maps for (b) U, (c) Mo, (d) Al, (e) $\mathrm{Si},(f) \mathrm{Mg}$, and $(g) \mathrm{Xe}$.
FIB samples taken from irradiated U-Mo dispersion fuels with $\mathrm{Al}$ alloy matrices. ${ }^{[32]}$ The phases at the fuel/ AA6061 cladding interface go amorphous during irradiation, and have regions that are $\mathrm{Si}$ rich and $\mathrm{Al}$ rich. Like was the case for dispersion fuel plates during irradiation, monolithic fuel plates also exhibit an enrichment of Xe at the IL/cladding interface near the Al-rich phases and fission gas bubbles in the Si-enriched portion of any interaction layers. Also, due to fission product recoil from the U-Mo fuel, fission products are transported microns into the Al-Si matrix or AA6061 cladding for dispersion and monolithic fuel, respectively. For both the irradiated U-Mo dispersion fuel and the irradiated U-Mo monolithic fuel, porosity and potential weakening of the interface between the IL and the Al-Si matrix or AA6061 cladding is typically observed.

In terms of the macroscopic irradiation performance of the fuel plates characterized as part of this study, one needs to consider the effect of using mini-plates to test fuel plates where bonding at the fuel/cladding interface may be a concern. Fuel plates L1F040 and L1F100 survived irradiation to an average fission density of $3 \times 10^{21}$ fissions $/ \mathrm{cm}^{3}$ without fission product release. However, it is not clear how constraint of the small-scale fuel plates by the irradiation device (e.g., constraint of the sample by the rails) may have affected the testing result. Since constraint may help hold a relatively small fuel plate together during irradiation, large-scale testing is required to adequately test a fuel system. Large-scale testing at more aggressive irradiation conditions will incorporate the more realistic stresses that an actual larger scale fuel plate will be exposed to and will help lessen the impact of constraint. Furthermore, the $\sim 25$ atmosphere pressure present in ATR may help keep the fuel/cladding interface intact during testing. Evidence of a possible weak interface has been uncovered 


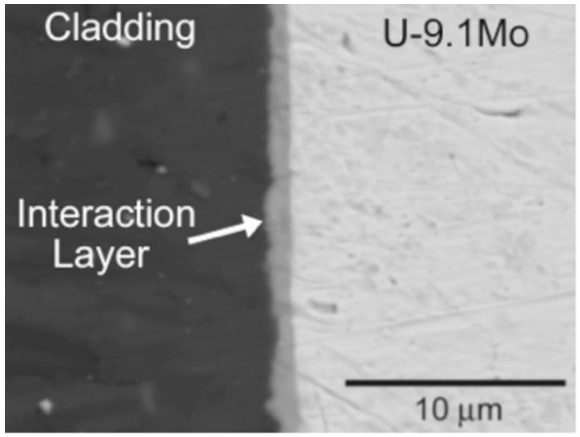

(a)

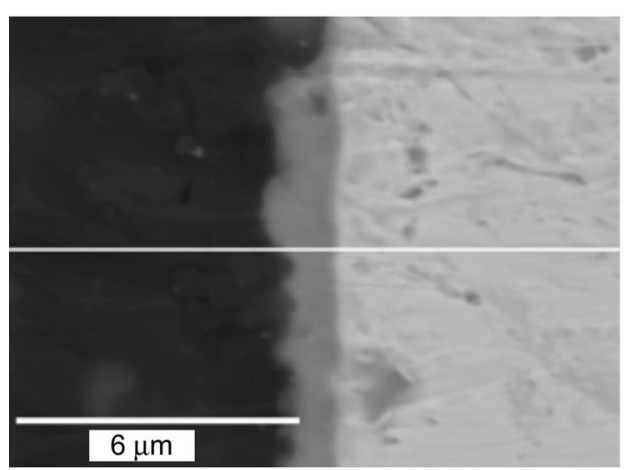

(c)

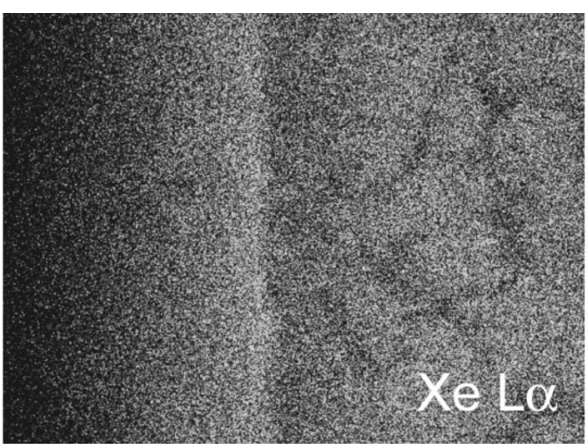

(b)

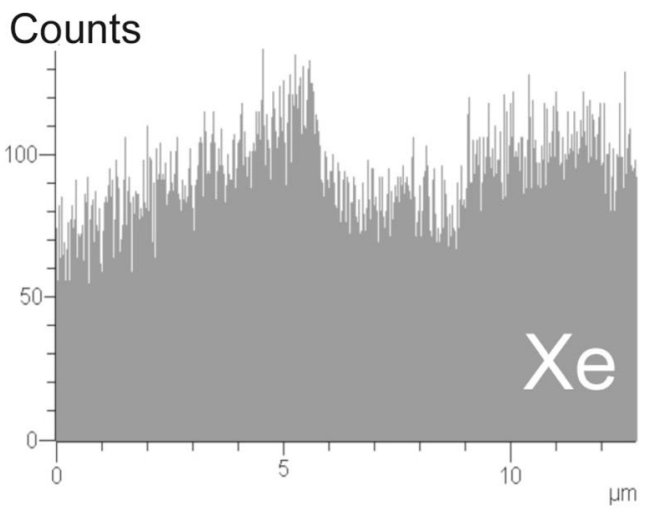

(d)

Fig. 14 -BSE image $(a)$ and Xe X-ray map $(b)$ at a location along the U-9.1Mo/AA6061 cladding interface for sample A. (c) is a BSE image showing where a Xe peak intensity scan was produced, and (d) shows the results for Xe.

during sample slicing of more highly irradiated, friction-bonded U-Mo fuel plates with AA6061 cladding as part of destructive examinations. During this procedure, debonding was observed, most typically at the interface between the interaction zone and the AA6061 cladding. ${ }^{[33]}$ This is the same interface that has been reported to be weak in $\mathrm{U}$ vs $\mathrm{Al}$ diffusion couples, ${ }^{[10]}$ and it is also the location where $\mathrm{Xe}$ was enriched during SEM analysis of L1F100 and L1F040. During irradiation to higher fission densities, the bond in question has the potential to continually weaken due to the presence of the porous, amorphous, brittle intermetallics at the fuel/cladding interface, and the continued buildup of fission gases, like Xe, at the interaction layer/AA6061 cladding interface.

To eliminate the extensive fuel/cladding interaction that can occur during fabrication of U-Mo monolithic fuel with AA6061 cladding, the potential for weak bonding at the fuel/cladding interface, and the development of amorphous, potentially brittle phases in the fuel/cladding interaction layers, the most recent design of the fuel employs a $\mathrm{Zr}$ diffusion barrier, which totally eliminates the deleterious U-Mo/AA6061 cladding interaction. ${ }^{[1,34]}$ Many successful irradiation experiments have been completed that demonstrate the robustness of the $\mathrm{Zr}$ diffusion barrier fuel design, whereby the development of the deleterious interaction layers described in this paper have been eliminated.

\section{CONCLUSIONS}

Based on the SEM characterization of U-9.1Mo/ AA6061, monolithic fuel mini-plates fabricated using a friction bonding process followed by a heat-treatment at $773 \mathrm{~K}\left(500{ }^{\circ} \mathrm{C}\right)$ for 30 minutes and the OM, SEM, and TEM charcterization of friction-bonded mini-plates irradiation-tested in ATR, the following conclusions 


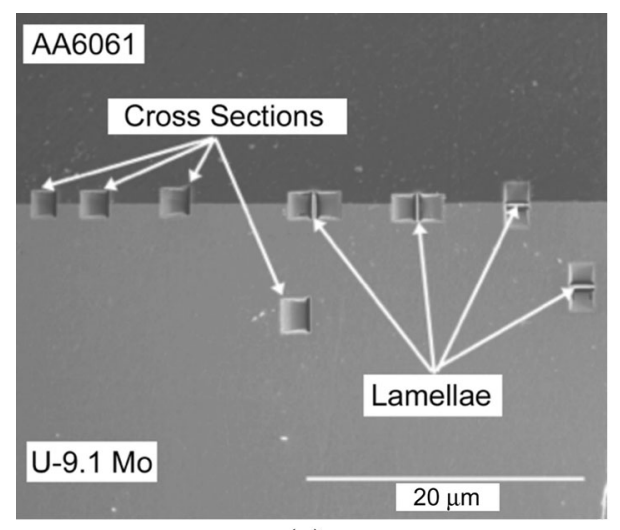

(a)

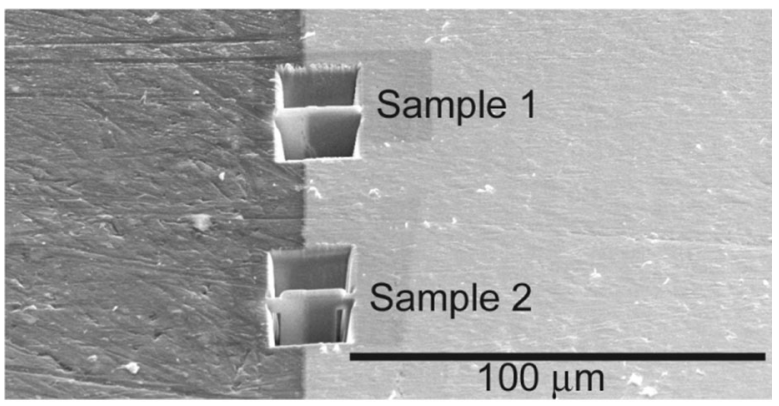

(b)

Fig. 15-SE image (a) showing where cross sections were generated to determine the representative microstructure for the sample, along with the lamellae that were eventually produced. (b) is an SE high-magnification image of the two FIB samples that were produced for analysis from the fuel/cladding interface for L1F040.

can be drawn about the interaction layers present at the U-9.1 Mo/AA6061 cladding interface:

1. After fabrication, friction-bonded mini-plates that are also heat treated at $773 \mathrm{~K} \quad\left(500{ }^{\circ} \mathrm{C}\right)$ for 30 minutes contain a Si-rich and $\mathrm{Al}$-rich interaction layer at the fuel/AA6061 cladding interface. These layers can vary widely in thickness, and the fraction of the interaction zone thickness that is composed of either the Si-rich or Al-rich phase can also vary widely. These layers are very similar to those observed for the as-fabricated U-Mo dis-

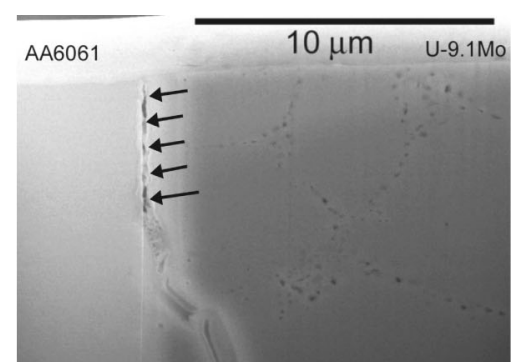

(a)

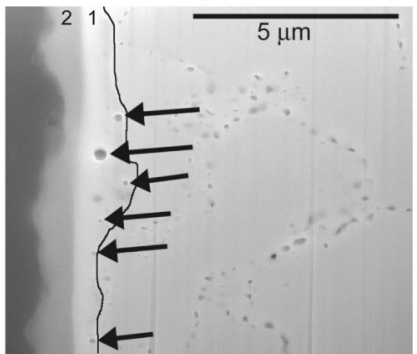

(b)

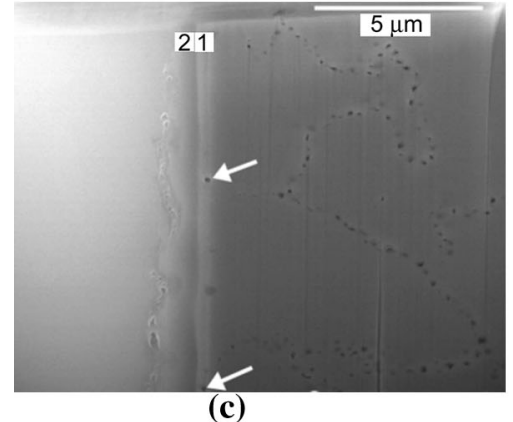

Fig. 16-SE image $(a)$ of a microstructure observed for the first FIB sample from sample A, where the black arrows depict possible debonding, and (b) shows a higher magnification SE image of the microstructure observed along the interface (a black line was drawn to show the boundary between layer 1 and the unreacted U-9.1Mo). (c) shows the microstructure for the second FIB sample from sample A. Into the U-9.1Mo fuel, fission gas bubbles can be observed along grain boundaries, and fission gas bubbles are also present in the Si-enriched layer 1 (arrows in (b) and (c) identify the bubbles).

persion fuel plates with Al-Si matrix in terms of composition.

2. During irradiation, the layers present at the U-9.1Mo fuel/AA6061 cladding interface in a monolithic fuel 


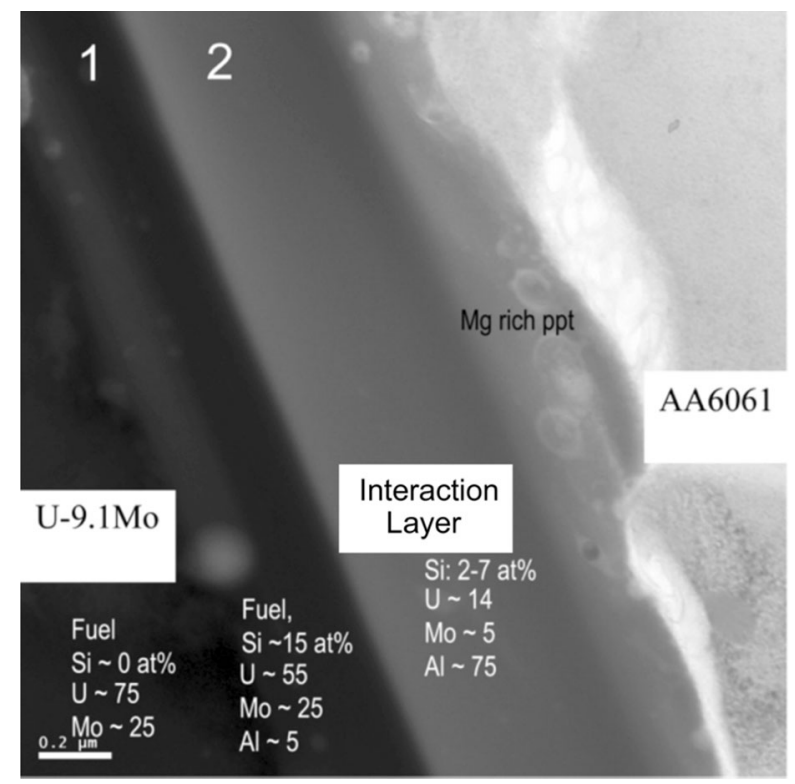

Fig. 17-TEM micrograph observed for L1F040 FIB sample produced at the U-9.1Mo/AA6061 cladding interface for sample A. Three regions identified (1) Fuel with Si and Al, (2) FMI layer, and (3) $\mathrm{Mg}$-rich precipitate (ppt) region.

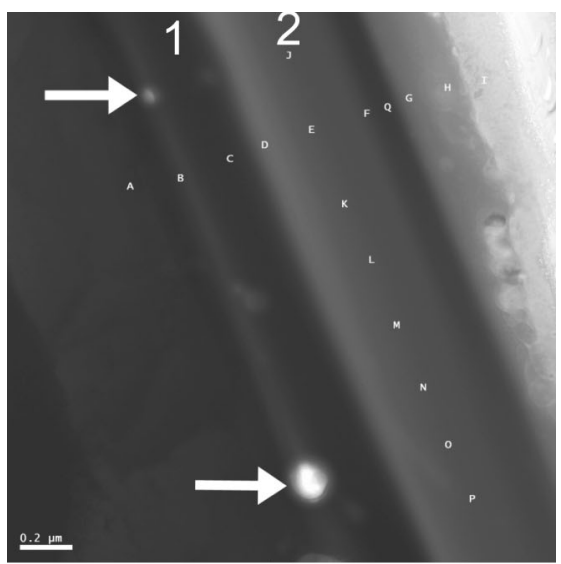

(a)

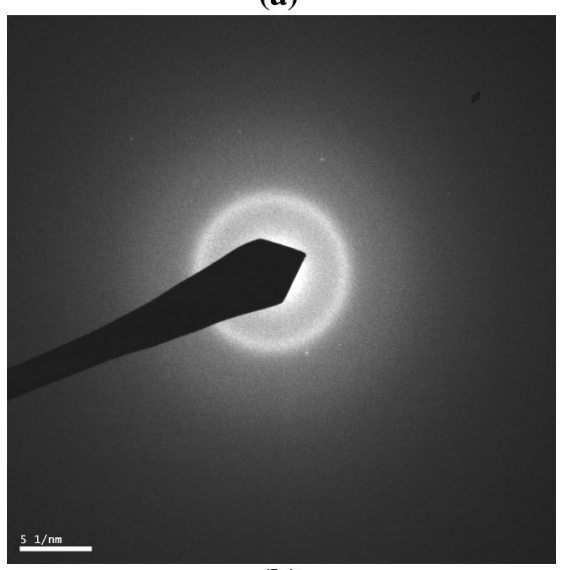

(b)

Fig. 18-TEM micrograph (a) with points where SEM/EDS compositional analysis was performed, and $(b)$ shows an electron diffraction pattern that was generated from the center of layer 2. The arrows in (a) show the fission gas bubbles present in the Si-rich layer (layer 1) that are similar to those shown in Fig. 16.

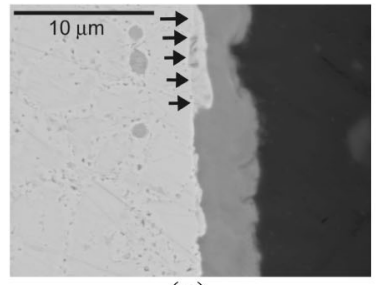

(a)

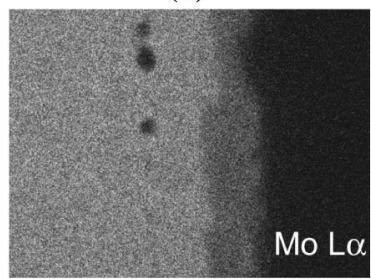

(c)

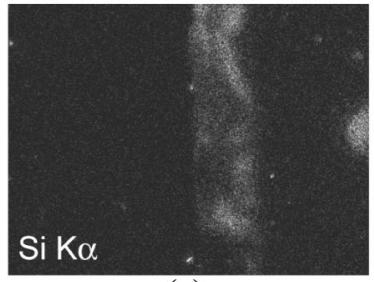

(e)

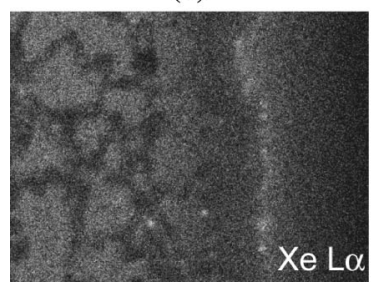

(g)

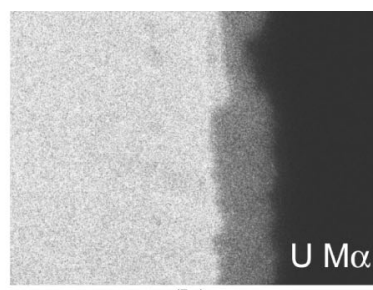

(b)

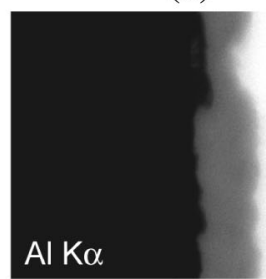

(d)

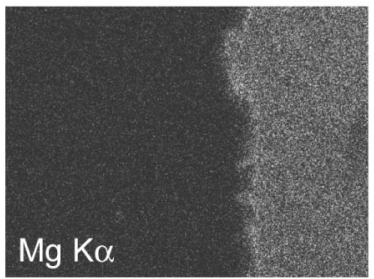

(f)
Fig. 19-BSE image (a) and X-ray maps for $(b) \mathrm{U},(c)$ Mo, (d) Al, (e) $\mathrm{Si},(f) \mathrm{Mg}$, and $(g) \mathrm{Xe}$. The arrows in (a) show where a Si-rich layer is present.

plate exhibit microstructural features that are similar to those reported for $\mathrm{U}-\mathrm{Mo} /$ matrix interaction layers in irradiated U-Mo dispersion fuels. The U-9.1Mo fuel/AA6061 cladding interaction layers become amorphous during irradiation. The Al-rich layer portion of the interaction zone contains very few fission gas bubbles, but does exhibit Xe enrichment near the AA6061 cladding interface, and the Si-rich layer contains more fission gas bubbles, compared to the Alrich layer. With respect to one of the major alloying constituents in AA6061 cladding, Mg appears in precipitates in a Mg-rich layer adjacent to the AA6061 cladding, and this layer is in close proximity to the region where Xe is observed to be enriched. At the interaction layer/AA6061 cladding interface, possible indications of porosity/debonding have been observed during characterization of FIB samples, indicating that the interface in this location may be relatively weak. 


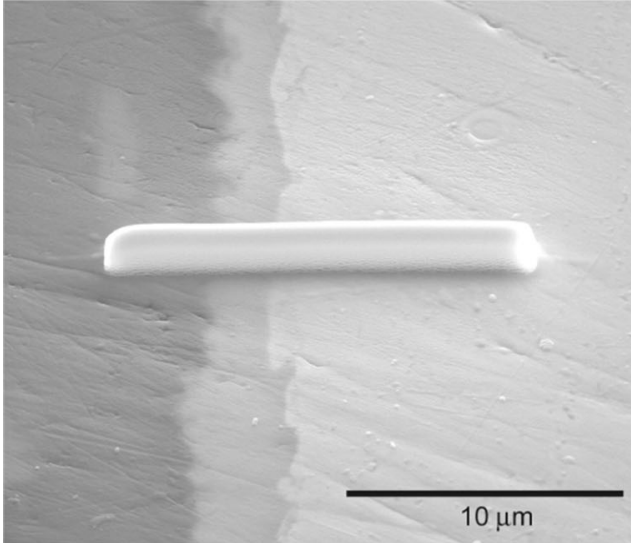

(a)

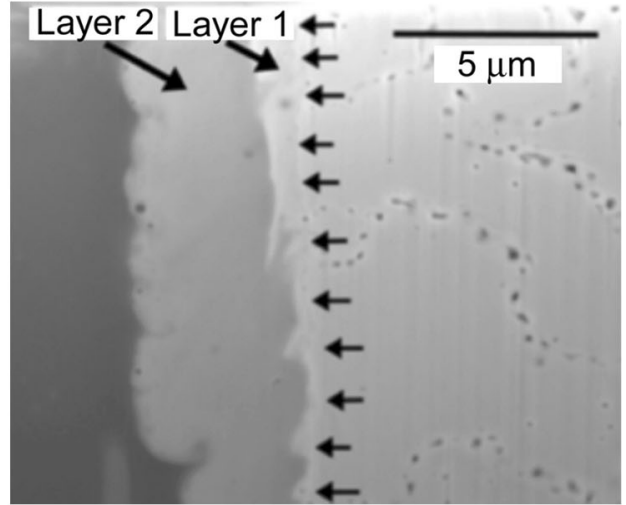

(c)

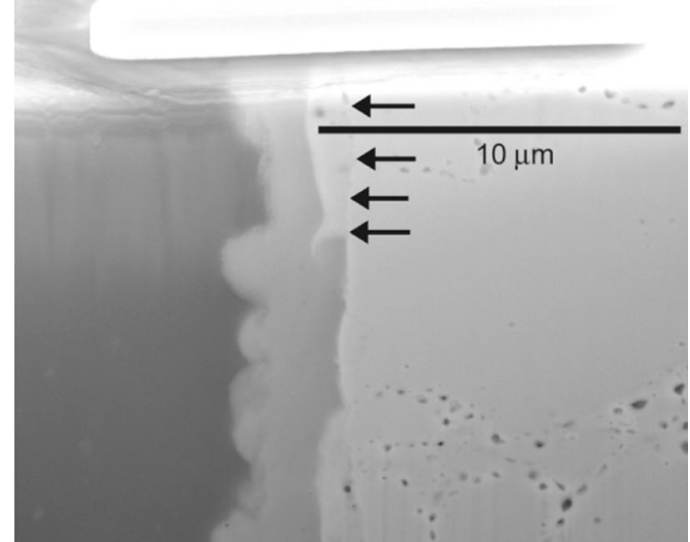

(b)

Fig. 20 - SE image (a) showing where Pt was deposited on the sample surface so that a FIB sample could be produced at that location. (b) Shows an SE image of the microstructure that was revealed during the FIB sample machining process, where arrows delineate the region where a Si-rich layer can be observed. (c) Shows an SE image of the microstructure at a different location along the U-9.1Mo/AA6061 cladding interface, where the Si-rich layer (Layer 1) and Al-rich layer (Layer 2) are observed along more of the U-9.1Mo/AA6061 cladding interface.

\section{ACKNOWLEDGMENTS}

This manuscript has been authored by Battelle Energy Alliance, LLC under Contract No. DE-AC0705ID14517 with the U.S. Department of Energy. The U. S. Government retains and the publisher, by accepting the article for publication, acknowledges that the U. S. Government retains a non-exclusive, paid-up, irrevocable, world-wide license to publish or reproduce the published form of this manuscript, or allow others to do so, for U. S. Government purposes. The HFEF staff, located at INL, is thankfully acknowledged for its contributions in performing PIE and generating punchings used for conducting the SEM analysis. Acknowledgment is given to the ATR staff for their assistance in performing the irradiation experiments. Acknowledgment is given to Ryan Collette for his efforts in performing image analysis.

\section{REFERENCES}

1. M.K. Meyer, J. Gan, J.F. Jue, D.D. Keiser, E. Perez, A. Robinson, D.M. Wachs, N. Woolstenhulme, G.L. Hofman, and Y.S. Kim: Nucl. Eng. Technol., 2014, vol. 46 (2), pp. 169-82.
2. D.E. Burkes, N.P. Hallinan, K.L. Shropshire, and P.B. Wells: Metall. Mater. Trans. A, 2008, vol. 39A, pp. 2852-61.

3. C.R. Clark, N.P. Hallinan, J.F. Jue, D. D. Keiser, Jr., J. M. Wight, Proc. of the 10th International Meeting on Research Reactor Fuel Management, Sofia, Bulgaria, April 30-May 3, 2006.

4. J.-F. Jue, B.H. Park, C.R. Clark, G.A. Moore, and D.D. Keiser, Jr.: Nucl. Technol., 2010, vol. 172, pp. 204-10.

5. E. Perez, D.D. Keiser, Jr., and Y.H. Sohn: J. Nucl. Mater., submitted for publication, 2015.

6. E. Perez, D.D. Keiser, Jr., and Y. Sohn: Idaho National Laboratory Report, April 2013, INL/EXT-13-28842.

7. IAEA: International Atomic Energy Agency Report, NF-T-5.2, Vienna, 2009.

8. M.R. Finley, D.M. Wachs, and G.L. Hofman: Proceedings of the 26th International Meeting on Reduced Enrichment of Research and Test Reactors, Cape Town, South Africa, October 29-November 2, 2006.

9. J.E. Cunningham and R.E. Adams: Proceedings of the Fuel Elements Conference, Paris, France 18-23 November, 1957, pp. $102-19$.

10. T.K. Bierlein and D.R. Green: HW-38982 Report, October 6, 1955.

11. D.E. Burkes, R. Prabhakaran, J.-F. Jue, and F. Rice: Metall. Mater. Trans. A, 2009, vol. 40A, pp. 1069-79.

12. Metals Handbook, Vol. 2-Properties and Selection: Nonferrous Alloys and Special-Purpose Materials, ASM International 10th ed. 1990.

13. S.J. Rothman: Argonne National Laboratory, ANL-5700. (May, 1961). p. 28. 
14. E. Perez, D.D. Keiser, Jr., and Y.H. Sohn: Metall. Mater. Trans. A, 2011, vol. 42A, pp. 3071-83.

15. E. Perez, Y.H. Sohn, and D.D. Keiser, Jr.: Metall. Mater. Trans. A, 2013, vol. 44A, pp. 584-95.

16. M.I. Mirandou, S.F. Arico, S.N. Balart, and L.M. Gribaudo: Mater. Charact., 2009, vol. 60, pp. 888-93.

17. D.D. Keiser, Jr.: Defect Diffus. Forum, 2007, vol. 266, pp. 131-48.

18. J.F. Jue, B.H. Park, C.R. Clark, G.A. Moore, and D.D. Keiser, Jr.: Nucl. Technol., 2010, vol. 172, pp. 204-10.

19. J. Gan, D.D. Keiser, Jr., B.D. Miller, M.A. Kirk, J. Rest, T.R. Allen, and D.M. Wachs: J. Nucl. Mater., 2010, vol. 407, pp. 48-54.

20. J. Gan, D.D. Keiser, Jr., B.D. Miller, D.M. Wachs, T.R. Allen, M Kirk, and J. Rest: J. Nucl. Mater., 2011, vol. 411, pp. 174-80.

21. D.D. Keiser, Jr., J. Gan, J.F. Jue, B.D. Miller, and C.R. Clark: Mater. Charact., 2010, vol. 61, pp. 1157-66.

22. D.D. Keiser, Jr., J.F. Jue, B. Yao, E. Perez, Y.H. Sohn, and C.R. Clark: J. Nucl. Mater., 2012, vol. 412, pp. 90-99.

23. D.D. Keiser, Jr., A.B. Robinson, J. Jue, P. Medvedev, D.M. Wachs, and M.R. Finlay: J. Nucl. Mater., 2009, vol. 393, pp. 311-20.

24. D.D. Keiser, Jr., J.F. Jue, A.B. Robinson, P. Medvedev, J. Gan, B.D. Miller, D.M. Wachs, G.A. Moore, C.R. Clark, M.K. Meyer, and M.R. Finlay: J. Nucl. Mater., 2012, vol. 425, pp. 156-72.

25. J. Gan, D.D. Keiser, Jr., B.D. Miller, A.B. Robinson, J.F. Jue, P. Medvedev, and D.M. Wachs: J. Nucl. Mater., 2012, vol. 424, pp. $43-50$.
26. J. Gan, D.D. Keiser, Jr., D.M. Wachs, A.B. Robinson, B.D. Miller, and T.R. Allen: J. Nucl. Mater., 2010, vol. 396, pp. 234-39.

27. D.D. Keiser, Jr., J.F. Jue, B.D. Miller, J. Gan, A.B. Robinson, P. Medvedev, J. Madden, D. Wachs, and M. Meyer: Nucl. Eng. Technol., 2014, vol. 46 (2), pp. 147-58.

28. A. Leenaers, S. Van den Berghe, E. Koonen, C. Jarousse, F. Huet, M. Trotabas, M. Boyard, S. Guillot, L. Sannen, and M. Verwerft: J. Nucl. Mater., 2004, vol. 335, pp. 39-47.

29. A. Leenaers, S. Van den Berghe, J. Van Eyken, E. Koonen, F. Charollais, P. Lemoine, Y. Calzavara, H. Guyon, C. Jarousse, D. Geslin, D. Wachs, D. Keiser, A. Robinson, G. Hofman, and Y.S. Kim: J. Nucl. Mater., 2013, vol. 441, pp. 439-48.

30. E. Schaber and G. Hofman: Idaho National Laboratory Report, June 2005, INL/EXT-05-00256.

31. D.M. Perez, M.A. Lillo, G.S. Chang, G.A. Roth, N.E. Woolstenhulme, and D.M. Wachs: Idaho National Laboratory Report, December 2011, INL/EXT-11-24282.

32. D.D. Keiser, Jr., J.-F. Jue, B.D. Miller, J. Gan, A.B. Robinson, P. Medvedev, J. Madden, D. Wachs, and M. Meyer: Nucl. Eng. Technol., 2014, vol. 46, pp. 147-58.

33. A.B. Robinson, D.M. Perez, D.L. Porter, G.L. Chang, D.D. Keiser, Jr., D.M. Wachs, and G.L. Hofman: Idaho National Laboratory report, July 2013, INL/EXT-09-16807.

34. J.F. Jue, D.D. Keiser, Jr., C.R. Breckendridge, G.A. Moore, and M.K. Meyer: J. Nucl. Mater., 2014, vol. 448, pp. 250-58. 